\title{
Parametrisation of the variety of human behaviour related to building energy consumption in the Town Energy Balance (SURFEX-TEB v. 8.2)
}

\author{
Robert Schoetter $^{1}$, Valéry Masson ${ }^{1}$, Alexis Bourgeois ${ }^{2}$, Margot Pellegrino ${ }^{3}$, and Jean-Pierre Lévy ${ }^{2}$ \\ ${ }^{1}$ CNRM UMR 3589, Météo-France/CNRS, 42 avenue Gaspard Coriolis, 31057 Toulouse Cedex 1, France \\ ${ }^{2}$ LATTS UMR 8134 CNRS, Ecole des Ponts ParisTech, Université Paris-Est Marne-la-Vallée, 6-8 avenue Blaise Pascal, \\ Champs-sur-Marne, 77455 Marne la Vallée Cedex 2, France \\ ${ }^{3}$ Lab'Urba-GU, Université Paris-Est Marne-la-Vallée, 5 boulevard Descartes, 77420 Champs-sur-Marne, France
}

Correspondence to: Robert Schoetter (robert.schoetter@meteo.fr)

Received: 20 March 2017 - Discussion started: 29 March 2017

Revised: 26 June 2017 - Accepted: 27 June 2017 - Published: 21 July 2017

\begin{abstract}
The anthropogenic heat flux can be an important part of the urban surface energy balance. Some of it is due to energy consumption inside buildings, which depends on building use and human behaviour, both of which are very heterogeneous in most urban areas. Urban canopy parametrisations (UCP), such as the Town Energy Balance (TEB), parametrise the effect of the buildings on the urban surface energy balance. They contain a simple building energy model. However, the variety of building use and human behaviour at grid point scale has not yet been represented in state of the art UCPs. In this study, we describe how we enhance the Town Energy Balance in order to take fractional building use and human behaviour into account. We describe how we parametrise different behaviours and initialise the model for applications in France. We evaluate the spatio-temporal variability of the simulated building energy consumption for the city of Toulouse. We show that a more detailed description of building use and human behaviour enhances the simulation results. The model developments lay the groundwork for simulations of coupled urban climate and building energy consumption which are relevant for both the urban climate and the climate change mitigation and adaptation communities.
\end{abstract}

\section{Introduction}

It is well known that the local climate differs between urban and surrounding rural areas. Phenomena such as the urban heat island (Arnfield, 2003), and the urban impact on moisture (Unger, 1999) and precipitation (Shepherd, 2005) have been described extensively. The specificity of the urban climate derives from the differences between urban and rural areas of the energy, water and momentum balances at the Earth-atmosphere interface (Oke, 1982). The surface energy balance in urban areas (Eq. 1; Christen and Vogt, 2004) consists of the net all-wave radiation $\left(R_{\text {net }}\right)$, the turbulent fluxes of sensible $\left(Q_{\text {sen }}\right)$ and latent $\left(Q_{\text {lat }}\right)$ heat, the storage $\left(Q_{\text {sto }}\right)$ and anthropogenic $\left(Q_{\text {ant }}\right)$ heat fluxes.

$R_{\text {net }}+Q_{\text {sen }}+Q_{\text {lat }}+Q_{\text {sto }}+Q_{\text {ant }}=0$

Urban areas are usually less vegetated than rural areas, which leads to larger (lower) negative values of $Q_{\text {sen }}\left(Q_{\text {lat }}\right)$ at daytime. The storage of heat in the construction materials leads to a larger diurnal amplitude of $Q_{\text {sto }}$ in urban areas compared to rural areas. The anthropogenic heat flux is related to human and animal metabolism, heating and air conditioning of buildings, electrical appliances, cooking, domestic hot water, traffic and industrial activities (Sailor, 2011). It can be an important part of the urban surface energy balance in areas with high population density and energy consumption (e.g. in cities like Tokyo; Kikegawa et al., 2003). It is particularly relevant during the cold season in the mid- and high latitudes, as the other components of the surface energy balance are small 
at that time (Kłysik, 1996; Hamilton et al., 2009; Chow et al., 2014).

The anthropogenic heat is released primarily inside buildings; traffic-related releases are a notable exception. Heating (air conditioning) can be the dominant part of $Q_{\text {ant }}$ during the cold (warm) season (Kłysik, 1996). The energy consumed inside buildings accounts for $\sim 40 \%$ of global primary energy consumption and $\sim 30 \%$ of global carbon dioxide emissions (Yang et al., 2014). About $50 \%$ of the building energy consumption is due to heating, ventilation and air conditioning. In Europe, and especially France, the building energy consumption can account for up to $50 \%$ of the primary energy consumption (Sailor, 2011).

The building energy consumption due to heating and air conditioning depends on the meteorological conditions and interacts with the urban climate. During the warm season, the waste heat due to air conditioning tends to amplify the urban heat island. Kikegawa et al. (2003) found that air conditioning can increase the urban heat island by 1 to $2 \mathrm{~K}$ in Tokyo. For Paris, despite a relatively low prevalence of air conditioning, de Munck et al. (2013) reported an exacerbation of the urban heat island between 0.25 and $1 \mathrm{~K}$. The amplification of the urban heat island can lead to an increase of the energy demand for air conditioning. In contrast, during the cold season, the urban heat island tends to reduce the building energy consumption. There is thus a negative (positive) feedback between the building energy consumption and the urban heat island during the cold (warm) season.

Due to the relevance of building energy consumption for the urban climate and greenhouse gas emissions, its spatiotemporal variability needs to be known. In addition, numerical simulations of the coupled urban climate and building energy consumption allow the impact of mitigation and adaptation measures implemented in urban areas to be quantified. One example is the use of white roofs to reduce the energy demand for air conditioning (Akbari et al., 2012).

Sailor (2011) reviewed different approaches to determine $Q_{\text {ant. }}$.

- The "inventory approach" is based on the disaggregation of low-resolution energy consumption data in space and time. The main disadvantages are the lack of detailed information on the spatial variability of energy consumption, the not precisely known diurnal, weekly and annual cycles of energy consumption and the difficulty of accounting for the dependency of building energy consumption on meteorological conditions.

- The "energy-budget-closure approach" attempts to determine $Q_{\text {ant }}$ as the residual of the observed urban energy balance (Eq. 1). This approach therefore requires turbulent, radiant and storage flux measurements, which are available for only a few sites. Further, the error propagation and the lack of knowledge concerning the footprint of the measurements lead to large uncertainties.
- The third approach is to simulate the building energy demand with numerical models. One option is to simulate a selection of buildings typical for a given urban area and then aggregate the energy demand (Heiple and Sailor, 2008; Nie et al., 2014). The main advantage of using building models is that they take many details of the building physics and human behaviour into account. However, they may rely on meteorological forcing data (e.g. a station located at an airport), which might not be representative of the meteorological conditions in the city centre, neglecting, for example, the urban heat island. To circumvent this issue, Kikegawa et al. (2003) coupled a building energy model (BEM) to an urban canopy parametrisation (UCP), which was itself coupled to a mesoscale atmospheric model. With this "UCP-BEM approach", the feedbacks between the urban climate and the building energy consumption can be taken into account. Kikegawa et al. (2003) were able to reproduce the sensitivity of the cooling energy consumption on air temperature for a business district in Tokyo using this technique.

Although the UCP-BEM approach allows the interactions between urban climate and building energy consumption to be studied, its practical applicability is currently limited.

- A UCP-BEM is designed to parametrise the effects of the buildings on the urban surface energy balance at spatial resolutions from $\sim 100 \times 100 \mathrm{~m}^{2}$ (very fine-scale mesoscale modelling) to $\sim 100 \times 100 \mathrm{~km}^{2}$ (for representation of urbanised areas in global climate models, Oleson et al., 2008). The building energy model included in a UCP therefore does not represent one single building, but rather the ensemble of buildings at grid point scale. Within one grid point there will be a diverse range of building use and human behaviour, which are known to be relevant for building energy consumption (Andersen, 2012). The variety of building use and human behaviour should therefore be taken into account in simulations of urban climate.

- A UCP-BEM requires various input parameters, with one part related to building use, equipment and human behaviour: for example the fraction of buildings equipped with heating and air conditioning systems and the way these are used, the internal heat release due to electrical appliances, and the practices concerning ventilation and shading. These parameters are often not well known for a given urban agglomeration.

In this study, we describe how we enhance the Town Energy Balance (TEB) (Masson, 2000) coupled to the BEM (Bueno et al., 2012) in order to parametrise the variety of building use and human behaviour related to building energy consumption. The enhancements of TEB are detailed in Sect. 2. In Sect. 3, we describe how we determine the 
model input parameters related to building use and human behaviour for applications in France. In Sect. 4, we evaluate the spatio-temporal variability of the building energy consumption simulated with our approach for the CAPITOUL observation campaign in Toulouse. Conclusions are drawn in Sect. 5.

\section{Enhancement of TEB to parametrise the variety of building use and human behaviour}

In this section, we first discuss the state of the art of the representation of human behaviour in urban canopy parametrisations (Sect. 2.1). Then, we describe the modifications we made to TEB to account for fractional building use and behaviour (Sect. 2.2). Detailed information on the representation of behaviours like heating, air conditioning, ventilation and shading is provided in Appendix A. We describe only those modifications of TEB that relate to human behaviour and the building energy model with respect to the version implemented in SURFEX-v7.3 described by Bueno et al. (2012) and Pigeon et al. (2014).

\subsection{Human behaviour in urban canopy parametrisations}

Urban canopy parametrisations have been developed to solve the surface energy, momentum and water balances in urbanised areas in order to provide the lower boundary conditions (e.g. radiative and turbulent fluxes) for atmospheric models. These UCPs take the different position, orientation and physical properties of urban facets into account by solving separate budget equations for the roof, wall and road. UCPs can be of the single-layer type, like the TEB (Masson, 2000) and the SLUCM (Kusaka et al., 2001), which do not vertically discretise the walls, or of the multi-layer type, like the Building Effect Parametrisation (BEP) (Martilli et al., 2002), which do. The mentioned UCPs represent the complex urban morphology in a simplified way by assuming that the buildings are oriented along street canyons. In TEB, only one urban morphology (building height, aspect ratio of the street canyons) is considered per grid point, whereas in BEP a distribution of building heights can be taken into account.

Since the main purpose of a UCP is to calculate the radiative and turbulent fluxes above urban areas, not much emphasis has been placed on the indoor conditions and human behaviour. Masson (2000) prescribes $17^{\circ} \mathrm{C}$ as the indoor boundary condition for the temperature of the wall and the roof. Kusaka et al. (2001) and Martilli et al. (2002) follow a similar approach. This assumes heating with a perfect heating system during the cold season. During the warm season, it assumes that buildings are air conditioned. However, the waste heat due to air conditioning is not released outside the buildings. Air conditioning thus acts as a non-physical energy sink (Thatcher and Hurley, 2012).
Due to the relevance of building energy consumption to urban climate and climate change mitigation and adaptation, the UCPs have been further developed in order to include more realistic building physics. Kikegawa et al. (2003) were the first to implement a building energy model in a UCP. It takes into account heat conduction, solar heat gains through the windows, and air exchange due to ventilation, as well as internal heat release due to electrical appliances and the occupants. They further consider that the waste heat due to air conditioning is released outside the buildings. Similar developments were made by Salamanca et al. (2009) for BEP, and Bueno et al. (2012) for TEB.

The state of the art UCP-BEM thus include various aspects of human behaviour related to building energy consumption. However, two important issues remain.

- The building energy model is meant to parametrise the effect of the ensemble of the buildings at grid point scale, rather than one single building. In reality, the behaviour-related parameters (e.g. design temperature for heating) often depend on the building use (e.g. residential or office), the equipment (e.g. type of heating system), the socio-economical and demographical status of the inhabitants (e.g. age). Due to the heterogeneity of most urban areas, there will often be a wide variety of building use and human behaviour at grid point scale, which may, depending on the type of city, be more diverse than urban morphology. A building block that is homogeneous in terms of morphological and architectural properties may be used in various ways (e.g. residential, office, commerce) and be inhabited by different people. The variety of building use and behaviour at grid point scale should therefore be taken into account, even though only one type of urban morphology is considered for one grid point.

- Human behaviour related to building energy consumption is often unsteady (e.g. adjustment of the design temperature for heating). In state of the art building simulation tools, statistical models that simulate transitions of human behaviours based on, for example, Markov chains, are implemented (Haldi and Robinson, 2011; Vorger, 2014). Such an approach is not useful for an UCP-BEM, since the ensemble of behaviours at grid point scale shall be represented. Abrupt transitions shall therefore not take place. Instead, smooth formulas of limited complexity need to be implemented to describe the behaviours.

In order to circumvent these issues, we modify TEB in order to optionally take fractional building use and human behaviour into account, and we adapt the representation of human behaviours to the requirements of an urban canopy parametrisation. A general overview of our modifications of TEB, the urban module of the externalised surface (SURFEX), is displayed in Fig. 1. 


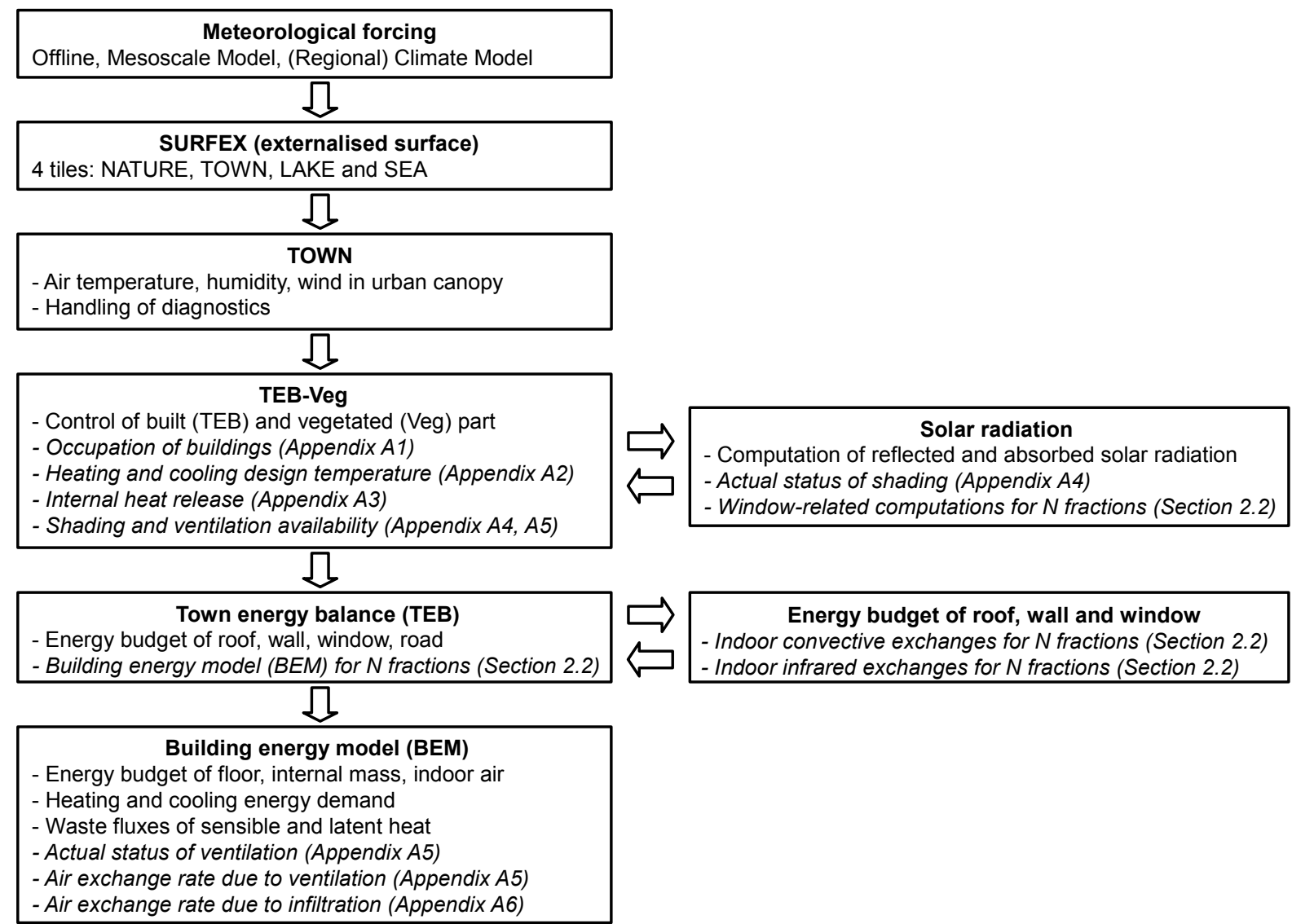

Figure 1. Overview of the components of SURFEX-TEB relevant to human behaviour and building energy consumption. The main modifications are in italics.

\subsection{Fractional building use and human behaviour in TEB}

\subsubsection{Main purpose of TEB enhancement}

The main purpose of our enhancement of TEB is to account for a potential variety of building use and human behaviour for one given urban morphology. This variety might be due to different uses and behaviours in buildings that are distinct but located in the same grid point and/or different uses and behaviours in the same building. These two cases, although different in reality, cannot be distinguished by TEB since the building energy model represents the entire building volume at grid point scale. A general overview of our approach for considering a variety of use and behaviour is given in Fig. 2 .

We assume that building use and human behaviour primarily influence the thermal environment inside the building (e.g. indoor air temperature) and only secondarily the conditions outside the building (e.g. air temperature in street canyon). For this reason, we modify TEB in order to optionally execute the building energy model different settings of the input parameters related to building use and human behaviour. This can be seen as simulating $N$ flats with differ- ent behaviours inside one building and/or $N$ separated buildings with different uses and behaviours. These concern the design temperature for heating and air conditioning, the internal heat release, ventilation and shading. The fraction of the $i$ th use/behaviour is denoted as $f_{i}$. The building energy model is simplified by taking into account only one single thermal zone for the indoor air. The intermediate floors are represented by a generic internal mass. The prognostic variables of BEM, which are the indoor air temperature $\left(T_{\text {air }}^{\text {ind }}\right)$ and specific humidity $\left(Q_{\text {air }}^{\text {ind }}\right)$, and the temperature of the internal mass $\left(T_{\text {mass }}\right)$ and building floor $\left(T_{\text {floor }}\right)$, are calculated for the $N$ fractional use/behaviours. A comprehensive list of symbols is included in Appendix C.

In contrast to the building energy model, the other components of TEB are solved only once at each time step. The components relevant for this study are

- the prognostic equations for the temperature of the building envelope (roof $\left(T_{\text {roof }}\right)$, wall $\left(T_{\text {wall }}\right)$ and window $\left(T_{\text {win }}\right)$ );

- the diagnostic equations for the air temperature $\left(T_{\text {air }}^{\mathrm{can}}\right)$ and specific humidity $\left(Q_{\text {air }}^{\text {can }}\right)$ in the street canyon; 

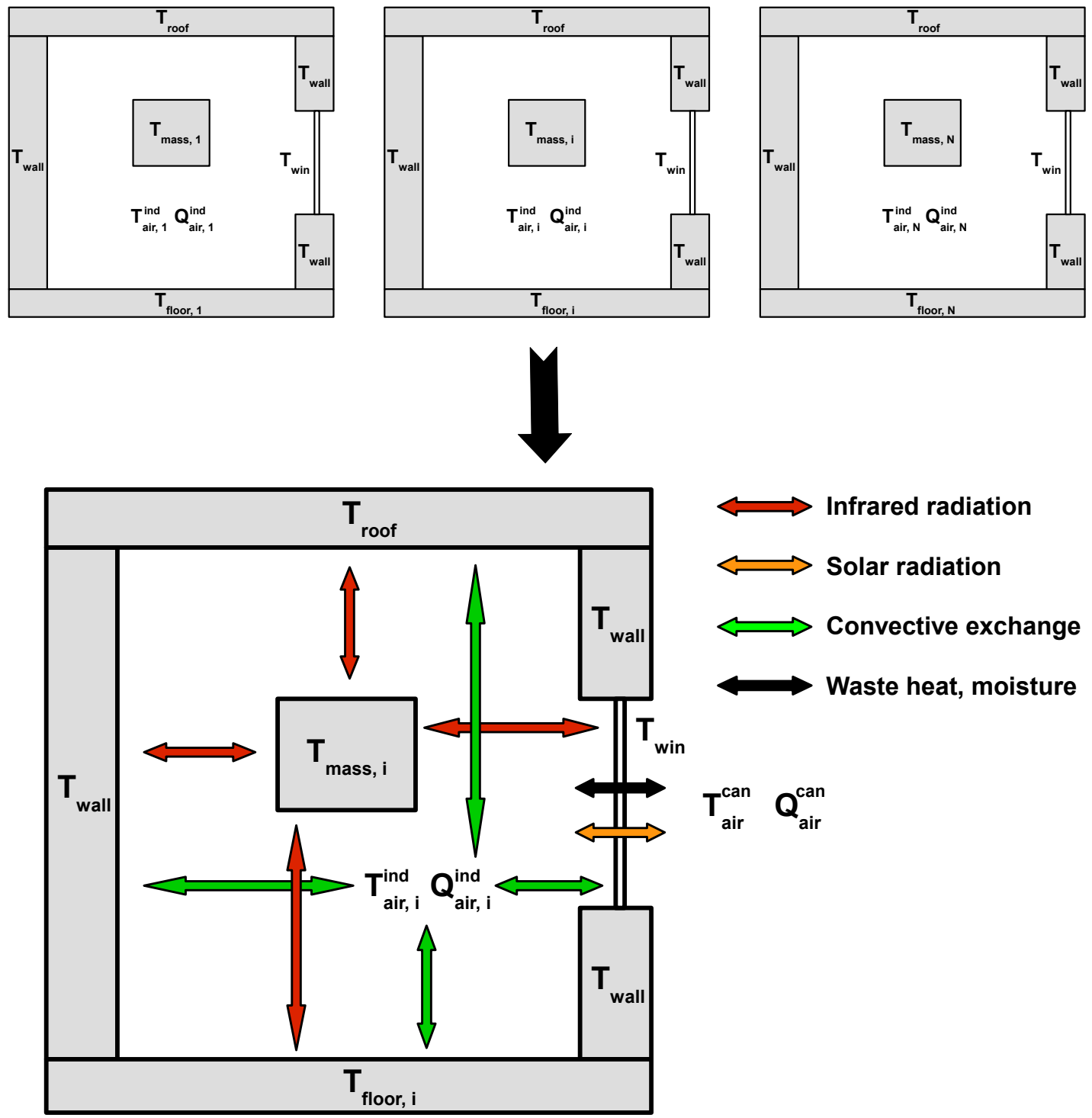

Infrared radiation

Solar radiation

Convective exchange

Waste heat, moisture

Figure 2. Overview of our methodology for parametrising fractional building use and human behaviour at grid point scale. For the $N$ different uses/behaviours we solve the equations for the indoor air and humidity, the internal mass and the ground floor $N$ times. The equations for the building envelope and the outside of the building are solved only once. The fluxes due to convection, shortwave and long-wave radiation and air exchange towards the roof, wall, window and the outside are aggregated over the $N$ fractional uses/behaviours. No direct exchanges between the different uses and behaviours are taken into account since we do not seek to represent exchanges between different compartments in one building.

- the budgets of shortwave and long-wave radiation outside of the building.

In order to link the components of TEB that are solved for the $N$ fractional building uses and behaviours and those that are solved only once, we aggregate the fluxes calculated for the $N$ fractional building uses and behaviours. The fluxes that need to be aggregated are

- the convective fluxes between the indoor air and the roof, wall and window;
- the fluxes of long-wave radiation between the floor and internal mass and the roof, wall and window;

- the fluxes of heat and moisture due to air exchange between the inside and the outside of the building (e.g. due to ventilation);

- the shortwave radiation reflected and absorbed by the windows.

We do not intend to represent exchanges between different compartments inside the building. For this reason, no direct 
exchanges between the $N$ fractional building uses and behaviours are taken into account.

\subsubsection{Modification of TEB Equations}

The convective heat exchange coefficients for the exchanges between the indoor air and the roof, wall and window are calculated separately for the $N$ fractions $\left(\mathrm{CHTC}^{\mathrm{air}, i}\right)$. This is necessary since they are strongly non-linear (Bueno et al., 2012). The convective heat fluxes from the roof $\left(H_{\text {roof }}^{\text {ind }}\right)$, wall $\left(H_{\text {wall }}^{\text {ind }}\right)$ and window $\left(H_{\text {win }}^{\text {ind }}\right)$ towards the indoor air are then aggregated over the $N$ fractions (Eqs. 2 to 4 ).

$$
\begin{aligned}
& H_{\text {roof }}^{\text {ind }}=\sum_{i=1}^{N} f_{i} \mathrm{CHTC}_{\text {roof }}^{\text {air }, i}\left(T_{\text {roof }}-T_{\text {air }, i}^{\text {ind }}\right) \\
& H_{\mathrm{wall}}^{\text {ind }}=\sum_{i=1}^{N} f_{i} \operatorname{CHTC}_{\mathrm{wall}}^{\text {air }, i}\left(T_{\mathrm{wall}}-T_{\mathrm{air}, i}^{\mathrm{ind}}\right) \\
& H_{\mathrm{win}}^{\text {ind }}=\sum_{i=1}^{N} f_{i} \mathrm{CHTC}_{\mathrm{win}}^{\mathrm{air}, i}\left(T_{\mathrm{win}}-T_{\mathrm{air}, i}^{\mathrm{ind}}\right)
\end{aligned}
$$

The exchanges of long-wave radiation between different facets inside the building (e.g. between the roof and the internal mass) are calculated based on the linearised StefanBoltzmann law, taking into account for infinite absorptions and reflections. The indoor radiative exchange coefficient is calculated separately for the $N$ fractions $\left(C_{\text {rad }, i}\right.$; Eq. 5).

$C_{\mathrm{rad}, i}=4 \epsilon_{1} \epsilon_{2} \sigma T_{\mathrm{rad}, i}^{3}$

The emissivity of all facets inside the building is assumed to be $0.9\left(\epsilon_{1}=\epsilon_{2}=0.9\right)$. The Stefan-Boltzmann constant is denoted by $\sigma$. The indoor mean radiative temperature for the $i$ th fraction $\left(T_{\mathrm{rad}, i}\right)$ is calculated following Eq. (6).

$$
\begin{aligned}
& T_{\text {rad }, i}= \\
& \frac{T_{\text {mass }, i} A_{\text {bld }}^{\text {mass }}+T_{\text {floor }, i}+T_{\text {wall }} A_{\text {bld }}^{\text {wall }}+T_{\text {roof }}+T_{\text {win }} A_{\text {bld }}^{\text {win }}}{A_{\text {bld }}^{\text {mass }}+1+A_{\text {bld }}^{\text {wall }}+1+A_{\text {bld }}^{\text {win }}}
\end{aligned}
$$

The temperatures of the different indoor facets are weighted by their surface ratios. For example, $A_{\text {bld }}^{\text {mass }}$ is the ratio between the surface of the internal mass and the building footprint. In Appendix B, we define how the surface ratios are calculated. The heat fluxes due to long-wave radiation (LW) between the wall, roof and window and the $N$ masses and floors are aggregated over the $N$ fractions (Eqs. 7 to 12).

$$
\begin{aligned}
& \mathrm{LW}_{\text {roof }}^{\text {mass }}=\sum_{i=1}^{N} f_{i} C_{\text {rad }, i}\left(T_{\text {roof }}-T_{\text {mass }, i}\right) \\
& \mathrm{LW}_{\text {roof }}^{\text {floor }}=\sum_{i=1}^{N} f_{i} C_{\text {rad }, i}\left(T_{\text {roof }}-T_{\text {floor }, i}\right) \\
& \mathrm{LW}_{\text {wall }}^{\text {mass }}=\sum_{i=1}^{N} f_{i} C_{\text {rad }, i}\left(T_{\text {wall }}-T_{\text {mass }, i}\right)
\end{aligned}
$$

$$
\begin{aligned}
& \mathrm{LW}_{\text {wall }}^{\text {floor }}=\sum_{i=1}^{N} f_{i} C_{\mathrm{rad}, i}\left(T_{\text {wall }}-T_{\text {floor }, i}\right) \\
& \mathrm{LW}_{\text {win }}^{\text {mass }}=\sum_{i=1}^{N} f_{i} C_{\mathrm{rad}, i}\left(T_{\text {win }}-T_{\text {mass }, i}\right) \\
& \mathrm{LW}_{\text {win }}^{\text {floor }}=\sum_{i=1}^{N} f_{i} C_{\mathrm{rad}, i}\left(T_{\text {win }}-T_{\text {floor }, i}\right)
\end{aligned}
$$

The heat loads on the indoor facets due to the shortwave radiation transmitted by the window $\left(\mathrm{SW}_{\mathrm{win}, i}^{\mathrm{tra}}\right)$ and the radiative fraction of the internal heat release $\left(\mathrm{QIN}_{\mathrm{rad}, i}\right)$ can be different for the $N$ fractions of building use and behaviour (e.g. shades closed in one part, but open in the remaining part of the building). The heat loads $(Q)$ received by the floor (Eq. 13) and internal mass (Eq. 14) are distinguished for the $N$ fractions, whereas the heat loads received by the roof (Eq. 15), wall (Eq. 16) and window (Eq. 17) are aggregated.

$$
\begin{aligned}
& Q_{\text {floor }, i}=\frac{V_{\text {floor }}^{\text {win }} \mathrm{SW}_{\text {win }, i}^{\text {tra }}+\mathrm{QIN}_{\mathrm{rad}, i}}{A_{\mathrm{bld}}^{\text {mass }}+1+A_{\mathrm{bld}}^{\text {wall }}+1+A_{\mathrm{bld}}^{\text {win }}} \\
& Q_{\mathrm{mass}, i}=\frac{V_{\mathrm{mass}}^{\operatorname{win}} \mathrm{SW}_{\mathrm{win}, i}^{\mathrm{tra}}+\mathrm{QIN}_{\mathrm{rad}, i}}{A_{\mathrm{bld}}^{\mathrm{mass}}+1+A_{\mathrm{bld}}^{\text {wall }}+1+A_{\mathrm{bld}}^{\text {win }}} \\
& Q_{\text {roof }}=\sum_{i=1}^{N} f_{i} \frac{V_{\text {roof }}^{\text {win }} \mathrm{SW}_{\text {win }, i}^{\text {tra }}+\mathrm{QIN}_{\mathrm{rad}, i}}{A_{\mathrm{bld}}^{\text {mass }}+1+A_{\mathrm{bld}}^{\text {wall }}+1+A_{\mathrm{bld}}^{\text {win }}} \\
& Q_{\mathrm{wall}}=\sum_{i=1}^{N} f_{i} \frac{V_{\mathrm{wall}}^{\mathrm{win}} \mathrm{SW}_{\mathrm{win}, i}^{\mathrm{tra}}+\mathrm{QIN}_{\mathrm{rad}, i}}{A_{\mathrm{bld}}^{\text {mass }}+1+A_{\mathrm{bld}}^{\text {wall }}+1+A_{\mathrm{bld}}^{\mathrm{win}}} \\
& Q_{\text {win }}=\sum_{i=1}^{N} f_{i} \frac{V_{\text {win }}^{\text {win }} \mathrm{SW}_{\text {win }, i}^{\text {tra }}+\mathrm{QIN}_{\text {rad }, i}}{A_{\text {bld }}^{\text {mass }}+1+A_{\text {bld }}^{\text {wall }}+1+A_{\text {bld }}^{\text {win }}}
\end{aligned}
$$

The shortwave radiation transmitted by the windows is multiplied by the corresponding view factors. For example, $V_{\text {floor }}^{\text {win }}$ is the view factor of the window by the floor. The calculation of the view factors is given in Appendix B. The propagation of shortwave radiation inside the building is assumed to be isotropic. This assumption is unchanged compared to previous versions of TEB.

The solar radiation reflected $\left(\mathrm{SW}_{\text {win }}^{\mathrm{ref}}\right)$ and absorbed $\left(\mathrm{SW}_{\mathrm{win}}^{\mathrm{abs}}\right)$ by the windows and the shading elements is aggregated over the $N$ fractions (Eqs. 18 and 19), since we do not differentiate the radiation budgets outside the building for the $N$ fractional uses and behaviours.

$$
\begin{aligned}
& \mathrm{SW}_{\mathrm{win}}^{\mathrm{ref}}=\sum_{i=1}^{N} f_{i} \mathrm{SW}_{\mathrm{win}, i}^{\mathrm{ref}} \\
& \mathrm{SW}_{\mathrm{win}}^{\mathrm{abs}}=\sum_{i=1}^{N} f_{i} \mathrm{SW}_{\mathrm{win}, i}^{\mathrm{abs}}
\end{aligned}
$$

The waste fluxes of sensible and latent heat $\left(H_{\mathrm{waste}, i}\right.$, $\mathrm{LE}_{\mathrm{waste}, i}$ ) can be due to infiltration, ventilation, heating and 
air conditioning. They are calculated separately for the $N$ fractional uses and behaviours (e.g. ventilation in one part of the building) and the resulting fluxes towards the street canyon (can) and the air above the roof (roof) are aggregated (Eqs. 20 to 23).

$$
\begin{aligned}
& H_{\text {waste }}^{\text {can }}=\sum_{i=1}^{N} f_{i} H_{\text {waste }, i}^{\text {can }} \\
& \mathrm{LE}_{\text {waste }}^{\text {can }}=\sum_{i=1}^{N} f_{i} \mathrm{LE}_{\text {waste }, i}^{\mathrm{can}} \\
& H_{\text {waste }}^{\text {roof }}=\sum_{i=1}^{N} f_{i} H_{\text {waste }, i}^{\text {roof }} \\
& \mathrm{LE}_{\text {waste }}^{\text {roof }}=\sum_{i=1}^{N} f_{i} \mathrm{LE}_{\text {waste }, i}^{\text {roof }}
\end{aligned}
$$

The following diagnostic variables of BEM depending on building use and human behaviour are available for the $N$ fractions:

- status of building occupation;

- status of shading and ventilation;

- air exchange rate due to ventilation;

- energy consumption due to internal heat release;

- energy consumption due to heating and air conditioning;

- indoor thermal comfort expressed by the Universal Thermal Climate Index (UTCI; Blazejczyk et al., 2012).

\subsubsection{Validation for idealised cases}

The advantage of the described approach for considering fractional building use and behaviour is that the computational costs are much lower compared to calling the entire SURFEX-TEB code $N$ times. However, this approach assumes that the variety of behaviours influences the inside of the building more than the outside. Uncertainties are introduced by averaging the fluxes towards the roof, wall and windows, since these represent the building envelope, which links the inside and the outside. For example, in the case where one part of the building is heated to $21^{\circ} \mathrm{C}$ whereas the other part is heated to $19^{\circ} \mathrm{C}$, the temperature of the wall will not be the same in the two parts of the building. For behaviours that only slightly modulate the indoor conditions, such simplifications are small compared to other simplifications of TEB, especially the single-layer assumption, which does not allow for distinction between the sunlit and shaded parts of the wall.

We perform one-dimensional "offline" simulations using the meteorological data observed at the meteorological tower during the CAPITOUL campaign (Sect. 4) as forcing to test how well different behaviours can be represented with our approach. We compare the simulated components of the urban surface energy balance (Eq. 1) for two model configurations.

- "Tile approach": two simulations with $N=1$ but different settings for input parameters related to human behaviour (e.g. different design temperature for heating). The simulated fluxes (e.g. $Q_{\text {sen }}$ ) for the two simulations are aggregated $50-50$.

- "Fractional approach": the same variety of behaviours as for the "tile approach" is represented by one simulation with $N=2$ and fractional behaviours with $f_{1}=$ 0.5 and $f_{2}=0.5$ (e.g. fractional design temperature for heating).

The "tile approach" represents the "true" solution in the case where there are different behaviours in separate buildings, which therefore (nearly) do not interact. The comparison between the "fractional approach" and the "tile approach" allows us to quantify the error made by simulated interactions between the different fractional behaviours that occur due to the aggregation of the fluxes towards the building envelope. We define that the "fractional approach" is sufficiently accurate if the average diurnal cycles of all components of the urban surface energy balance are simulated for all seasons with a mean absolute error of less than $5 \mathrm{~W} \mathrm{~m}^{-2}$ and less than $10 \%$ of the differences between the two "tile approach" simulations.

We find that the "fractional approach" is sufficiently accurate if the different use/behaviour do not cause too large a difference in the indoor air temperature. This is the case for different heating and air conditioning design temperatures, fractional ventilation and shading. The only exception is when parts of the buildings are not heated and isolated from the heated buildings. In this case, the difference in the indoor air temperature between the heated fraction and the non-heated fraction becomes so large that relative errors of $\sim 20 \%$ appear. The "fractional approach" can therefore be used for urban tissues where the non-heated part of a building is not completely isolated from the heated part. Otherwise a "tile approach" separating the heated and non-heated buildings should be used.

\section{Building use and human behaviour in France}

The enhancement of TEB described in Sect. 2 allows for the variety of building use and human behaviour at grid point scale to be represented. Detailed information on the urban area of investigation is required to make use of these enhancements. Human behaviours related to building energy consumption depend on the socio-economical characteristics of the population and cultural practices. For example, air conditioning is very common in large parts of the USA 
(Sailor and Pavlova, 2003), whereas it is rare in western Europe. Such information is crucial for a precise simulation of building energy consumption. The determination of all relevant information on building use and behaviour for the entire world is beyond the scope of this study.

In this section, we derive these data for France and describe how we take them into account in the enhanced version of TEB. Our general approach is to assign the behaviourrelated parameters of TEB as a function of building use. In Sect. 3.1, we describe the datasets we exploit, in Sect. 3.2 how we determine building use. In Sect. 3.3 and 3.4 we describe how we derive the TEB input parameters related to human behaviour. Finally, in Sect. 3.5 we provide the model configuration for simulation of urban climate and building energy consumption in France.

\subsection{Datasets}

In France, administrative datasets that provide centralised information on the morphology and use of buildings and the socio-economical status of the population are readily available. The following administrative datasets are used here:

- The French Geographical Institute (IGN) compiles a digital cadastre (the IGN-BDTOPO) providing information on building morphology and use for every building in France (http://professionnels.ign.fr/bdtopo). This dataset is regularly updated; we use the version from 2014.

- The French Institute on Economics and Statistics (INSEE) conducts a census of the entire French population (the INSEE-Census). It provides information on the socio-economical status (e.g. age, sex, professional situation) of each person as well as on household equipment (e.g. type of heating system) and composition (e.g. habitable floor area, number of inhabitants). Here we use data from the most recent complete census, performed in 2011. To protect privacy, the census data are aggregated over about 2000 individuals. The spatial resolution therefore depends on the population density and is as low as $\sim 300 \times 300 \mathrm{~m}^{2}$ in dense city centres. Data can be retrieved via https://www.insee.fr/fr/statistiques/ 2011208 ? sommaire $=2011338$

- The INSEE also provides the population density in gridded form (hereafter INSEE-Density). The resolution is $200 \mathrm{~m} \times 200 \mathrm{~m}$, we use the 2010 version. Data can be retrieved via https://www.data.gouv.fr/fr/datasets/ donnees-carroyees-a-200-m-sur-la-population/

The data on building morphology included in the IGNBDTOPO have been used by Amossé (2015) to determine the "urban typology" via statistical classification. It describes the building type and alignment (e.g. "detached low rise", "continuous rows of mid-rise", "extended low rise"). The urban typology is comparable to a French version of the built- up classes included in the local climate zone classification by Stewart and Oke (2012). It can provide valuable information on building use. For example, "detached low rise" corresponds mainly to individual housing, while "extended low rise" is typical for commercial or industrial buildings.

The administrative datasets cover all of France, but they do not include details on energy-related human behaviour. More detailed surveys on these aspects are thus required. The following are used in this study:

- The ENERGIHAB survey (Lévy and Roudil, 2012) provides information on energy-related behaviours for 1950 households in the Paris region (Ile de France). Data are available on the design temperature for heating, the electrical appliances installed and the frequency of their use, and practices concerning ventilation and shading. ENERGIHAB contains only very little information on air conditioning, since it is not common in the Paris region.

- The INSEE conducts regular surveys on practices related to building energy consumption, the "Enquête Nationale sur le Logement" (ENL). Here we use the surveys from 2006 and 2013. These comprise a sample of $\sim 36000$ households ( $\sim 27000$ households) for 2006 (2013) distributed over all of France. The ENL survey contains information on electricity consumption and the presence of air conditioning. However, there is no information on how air conditioning is used.

The exploration of the administrative datasets, surveys and our a priori knowledge of the climatic and cultural situation of France allows us to determine basic information about energy-related human behaviour. As nearly all homes are equipped with heating systems, heating during the winter contributes considerably to the building energy consumption and thus needs to be taken into account. On the other hand, air conditioning is rare in residential buildings, with a national average installation rate of $3.2 \%(6.7 \%)$ in 2006 (2013). Even in the regions close to the Mediterranean, which experience the mildest climate, the installation rate is only $12.8 \%(24.6 \%)$ in 2006 (2013). Instead of air conditioning, people tend to use shading elements to limit solar heat gains, along with ventilation in the evening. In office buildings, air conditioning is more frequent, but the market is far from saturated.

\subsection{Building use}

Our general approach is to assign the behaviour-related parameters of TEB as a function of building use. Information on building use is available in the IGN-BDTOPO. Four main categories of building use are defined for each building: industry, commerce, agriculture and "undefined". This basic information allows us to identify industrial and agricultural buildings as well as large commercial buildings. In addition, 
all buildings of public interest (e.g. schools) are indicated in the IGN-BDTOPO. By combining this information, we can distinguish between residential (individual and collective), office, commerce, education, public health, industry, agriculture, religious and sport use, as well as identify castles and non-heated buildings.

However, one important aspect of French cities is not described in the administrative datasets. In French city centres, many formerly purely residential buildings have been partially converted to commercial and/or office buildings. For example, the ground floor of nearly all buildings close to the city centres is occupied by small shops or restaurants, which are not declared as commerce in the IGN-BDTOPO. This is relevant to the modelling of building energy consumption, since the schedules of occupation and the use of the commercial and office part of these buildings differ substantially from that of the residential part.

In order to determine the fraction of commercial and office buildings we use the data on urban typology, the INSEEDensity, and our a priori knowledge of French cities.

- The urban typologies "detached low rise", "detached mid-rise" and "semi-detached low rise" correspond mainly to individual houses in suburban areas or town houses. We therefore assume that their use is purely residential.

- We assume that "extended low rise" buildings of "undefined" use in the IGN-BDTOPO are industrial buildings.

For the remaining urban typologies of "undefined" use, we take into account the number of inhabitants $N_{\text {inh }}$ per building floor area $\left(A_{\text {floor }}\right)$. High-rise buildings are not very common in France and only seldom of mixed use. We therefore only distinguish purely office use in the case where $\frac{N_{\text {inh }}}{A_{\text {floor }}}>120 \mathrm{~m}^{-2}$ and purely residential use otherwise.

For the other urban typologies, we assume that there is a non-residential fraction $\left(f_{\text {nres }}\right)$ in the case where $\frac{N_{\text {inh }}}{A_{\text {floor }}}>$ $60 \mathrm{~m}^{-2}$ (Eq. 24). This threshold is based on the value of the habitable floor area per inhabitant in residential buildings averaged over France, which is $36 \mathrm{~m}^{2}$ in 2011 (MEDDE, 2012). We increase this value to $60 \mathrm{~m}^{2}$ to account for the non-habitable floor area of buildings (elevators, staircase, attics and so on). However, this is only a gross assumption and therefore a considerable source of uncertainty since, for example, the habitable floor area per inhabitant might vary between different cities.

$f_{\text {nres }}=\max \left(0,1-\frac{60 N_{\text {inh }}}{A_{\text {floor }}}\right)$

We further divide the area of the building footprint $\left(A_{\text {foot }}\right)$ by the total floor area to obtain the ground floor fraction $\left(f_{\text {ground }}\right.$; Eq. 25).

$f_{\text {ground }}=\frac{A_{\text {foot }}}{A_{\text {floor }}}$
- For the urban typology "continuous row of mid-rise", we assume that the ground floor might be entirely occupied by stores since this urban typology is very typical for the centre of French cities (e.g. Fig. 5d). The resulting fraction of commercial use $\left(f_{\text {com }}\right)$ is given by Eq. (26). For the buildings whose non-residential fraction is larger than the commercial fraction, we assign an office fraction $\left(f_{\text {off }}\right)$ according to Eq. (27).

- For "discontinuous row of low (mid)-rise" and "continuous row of low rise", the same approach is used as for "continuous row of mid-rise". However, only up to half of the ground floor can be occupied by stores; the remaining non-residential fraction is assigned as office space.

$f_{\text {com }}=\min \left(f_{\text {ground }}, f_{\text {nres }}\right)$

$f_{\text {off }}=\max \left(f_{\text {nres }}-f_{\text {ground }}, 0\right)$

Based on the building use data at building scale, we define the dominant building use as the building use with the largest floor area at grid point scale. In Fig. 3, we display the dominant building use and the fraction of commercial use for the domain covering the agglomeration of Toulouse, for which we will conduct the evaluation of building energy consumption in Sect. 4. The dominant building use (Fig. 3a) is mainly collective housing close to the city centre and individual housing in suburban areas. However, considerable parts of the domain are covered by university campuses, large commercial buildings, and industrial zones. The information included in the IGN-BDTOPO allows us to identify these building uses. The fraction of commercial use is mainly between 0.1 and 0.2 close to the centre of the city, which represents the presence of shops on the ground floor of the buildings, which is common in this area.

It must be kept in mind that the approach to determine building use described in this section is tailored to the structure of French cities and the availability of administrative datasets. Different approaches are needed for other regions of the world. Kunze and Hecht (2015) have shown that information on (fractional) building use might be derived from collaborative geographical datasets like OpenStreetMap. Such approaches are promising, since in many regions no detailed administrative datasets exist.

\subsection{Human behaviour in residential buildings}

Bourgeois et al. (2017) developed statistical models, calibrated with data from the ENERGIHAB survey that allow the prediction of indicators related to human behaviour based on the INSEE-Census data. Since these are available for each person in France, maps of the behavioural indicators can be produced for the entire country. Details concerning the methodology of Bourgeois et al. (2017) are not repeated here. The following information is used: 
(a)

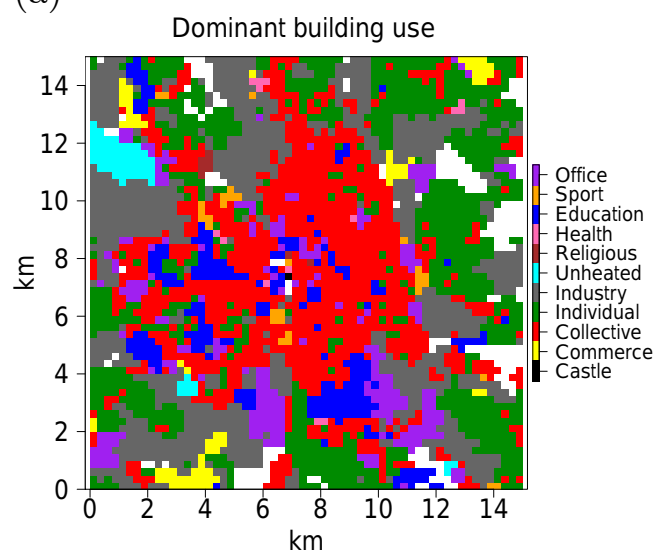

(b)

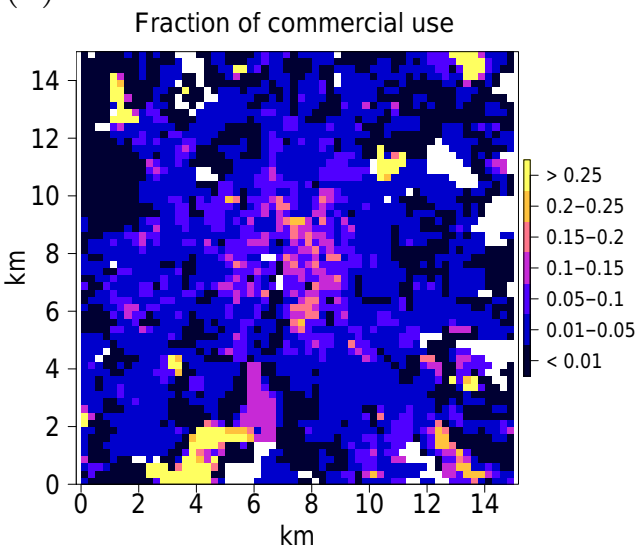

Figure 3. Spatial distribution in the agglomeration of Toulouse, France, of (a) dominant building use at grid point scale and (b) fraction of commercial use. The horizontal resolution is $250 \mathrm{~m} \times 250 \mathrm{~m}$.

- The efficiency tendency (ET) (ECR in Bourgeois et al., 2017) indicates to which degree inhabitants tend to regulate equipments related with building energy consumption. For implementation in TEB we only consider the relationship between ET and the use of the heating system. In households with high (low) ET, the design temperature for heating is on average lower (higher) and more likely to be reduced when the building is vacant or during the night. Furthermore, for high (low) ET a larger (smaller) part of the building is not heated. The ET is lower for collective than for individual heating systems. This is consistent with previous findings (Guerra Santin, 2013; Kelly et al., 2013). ET also depends on the type of fuel used in the heating system (electrical heating, gas, etc.). ET is high for electrical heating systems, which is plausible, since they are easy to adjust. ET tends to decrease with increasing age of the household reference person. This confirms previous studies indicating that elderly people tend to heat more (Motuziene and Vilutiene, 2013; de Meester et al., 2013). The statistical model of Bourgeois et al. (2017) predicts whether one household will be of high or low ET (two classes). For this reason, we take the values of the heating design temperature and the non-heated fraction of the buildings available from the ENERGIHAB survey and average them for the households falling into the high and the low ET class, respectively. These values (Table A3) are used to initialise TEB for the residential buildings.

- Bourgeois et al. (2017) also defined indicators related to equipment with large household appliances (EQ) and the intensity of use of large electrical appliances (IU). Similar to ET, there are two classes (high and low) for both EQ and IU. For the purpose of urban climate modelling we are only interested in the actual heat release due to electrical appliances. We therefore combine the
EQ and IU indicators to the equipment-intensity-of-use (EIU) indicator. It has three classes. High EIU corresponds to high EQ and high IU, low EIU to low EQ and low IU and medium EIU to high (low) EQ in combination with low (high) IU. The EIU tends to be higher for a larger number of inhabitants per household and for a smaller habitable floor area. This is unsurprising since more inhabitants per habitable floor area will lead on average to more use of electrical appliances. Bourgeois et al. (2017) calculate the average electricity consumption available from the ENL dataset for the 3 classes of the EIU indicator. These values are used to initialise the parameters related to the internal heat release in TEB (Table A4). The electricity consumption due to domestic warm water has been excluded from the ENL dataset. This is justified for urban climate modelling, since a large part of the energy exits the building through pipes and into the sewage system (Heiple and Sailor, 2008). The internal heat release due to metabolism is also not included, since in industrial countries it is often negligible compared to the other components of the anthropogenic heat flux (Grimmond, 1992). Metabolic heat may have to be included for cities in developing countries.

- No robust statistical relationships between the behaviours related to ventilation and shading and the INSEE-Census data have been found by Bourgeois et al. (2017). The spatial variability of these behaviours can therefore not be taken into account. Nevertheless, the fraction of people applying ventilation and shading during warm conditions and during the night could be derived from the ENERGIHAB data (Table A5).

The statistical models developed by Bourgeois et al. (2017) are used to predict the behavioural indicators for each household and we then derive maps of the fraction of households 
with high ET as well as with high and low EIU. The behavioural indicators differ systematically between collective and individual housing. Thus, for each behavioural indicator, we produce a map for collective and individual housing. These maps are read by TEB, and we describe in Sect. 3.5 how we further use the indicators. In Fig. 4, we display maps of the ET and EIU indicators for the city of Toulouse as an example. The spatial variability of the ET indicator (Fig. 4a) is mainly due to the spatial distribution of the heating system type and the fuel type used in the heating system. These can differ considerably in different parts of the urban agglomeration. The spatial variability of the EIU indicator (Fig. 4b) is due to the spatial distribution of the number of inhabitants per habitable floor area.

\subsection{Behaviours in non-residential buildings}

The behavioural indicators are not used in non-residential buildings. Instead, the behaviour-related parameters are initialised as a function of the building use via lookup tables.

The values of the design temperature for heating and air conditioning are given in Table A3. We assume that air conditioning is used in "offices", "commerce" and "public health". We choose a relatively high design temperature of $28^{\circ} \mathrm{C}$, since we know that not all such buildings are air conditioned in France. Educational buildings are used only rarely during the warm season (holidays) and are therefore not equipped with air conditioning. For "industry" we assume that only a small fraction (0.05) of the building is heated. We apply only little to no heating for the uses "agriculture", "religious", "sport", "castle" and "non-heated".

The values for the internal heat release and its modulation during vacancy and at night are given in Table A4. For the building uses "office", "commerce", "public health" and "education", we assume higher values of the internal heat release than for residential buildings in order to represent the higher density of electrical appliances and/or the larger density of occupation. For industrial buildings we do not consider that some buildings might be power plants or other large energy consumers. Such facilities need to be taken into account by using an inventory of large energy consumers.

The contribution of lighting to the total internal heat release is only 5 to $15 \%$ (Yun et al., 2012), which does not justify a detailed modelling (e.g. depending on indoor illumination) for urban climate simulations. Apart from lighting, the radiative part of internal heat release includes also emission of long-wave radiation from electrical appliances, which can be relatively important (e.g. up to $40 \%$ for computers; Hosni et al., 1999). We therefore consider a radiative part of the internal heat release of 0.4 for office and commercial uses and 0.2 for all building uses.

We assume that no shading is made for the non-residential buildings (Table A5). Buildings of this type are normally not equipped with shading elements in France. Since we assume air conditioning for the office, commerce and public health buildings, no overheating will occur for these building uses. Ventilation is only included in educational buildings, since these are not equipped with air conditioning.

\subsection{Representation of building use and human behaviour for urban climate simulations in France}

Based on our knowledge of the variety of building use and human behaviour in France and its relevance for building energy consumption, we define the TEB configuration for urban climate and building energy consumption simulations in France. Depending on the dominant building use, we distinguish up to six fractions of sub-grid-scale building use and human behaviour (Table 1).

- For grid points with dominant residential use, we distinguish a total of six fractional uses and behaviours. We consider for a non-heated, a commerce, an office and a residential fraction with three different design temperatures for heating. The values of the commerce and office fractions are given by the maps of $f_{\text {com }}$ and $f_{\text {off }}$ described in Sect. 3.2, the values for the non-heated fraction are given in Table A3. In the commerce and office fraction, the schedules of building occupation and all input parameters related to human behaviour correspond to the values defined for the uses "office" and "commerce". In the non-heated fraction there is no heating, air conditioning or internal heat release. In the residential fraction, we consider three different design temperatures for heating. They correspond to the values for high and low ET (Table A3) and their arithmetic average. The occurrence frequencies of these three different design temperatures ( $f_{\text {low }}, f_{\text {med }}$ and $f_{\text {high }}$; Eqs. 28 to 30) are initialised based on the maps of the ET indicator (e.g. Fig. 4a). However, due to the strong variability of the human behaviours, even for the hypothetical case that all households at grid point scale fall into the highET class $\left(f_{\mathrm{ET}}^{\text {high }}=1\right)$, not all households heat to the design temperature averaged over the high-ET class. For this reason, the fraction of households with high ET in Eqs. (28) to (30) is multiplied with the corresponding conditional probability given in Table A6. For example, $p_{T-\text { low }}^{\text {HighET }}$ is the probability that a household will heat to the lower design temperature given that it belongs to the high-ET class.

- For grid points with dominant uses "office", "commerce", "public health" and "education", we distinguish four fractions: the non-heated fraction and three different design temperatures for heating or air conditioning. We assume that one-third of the floor area is heated to the design temperature given in Table A3 and one-third to $2 \mathrm{~K}$ lower and higher, respectively. A similar approach is used for air conditioning, except that educational buildings are not air conditioned at all. 

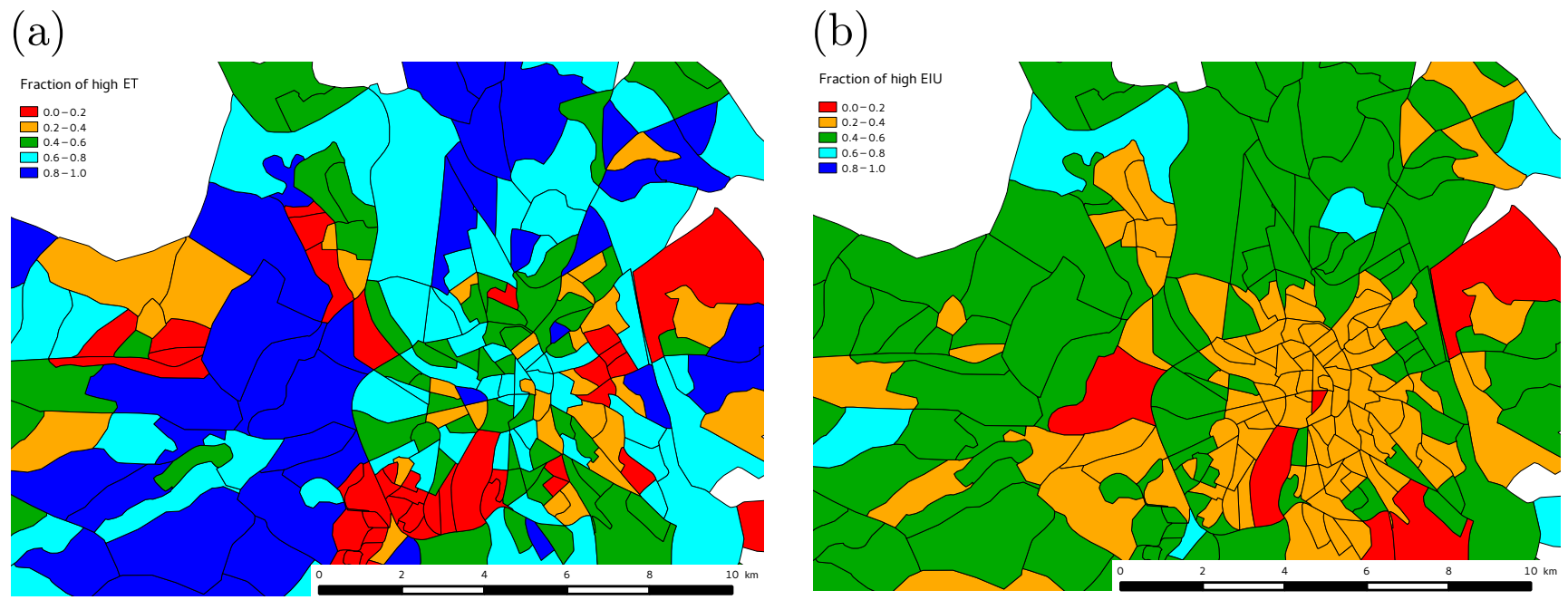

Figure 4. Spatial distribution in the agglomeration Toulouse of (a) fraction of households with high efficiency tendency (ET) and (b) fraction of households with high equipment-intensity-of-use (EIU). The spatial variability is introduced by the predictors of the statistical models described in Bourgeois et al. (2017). These are the heating system type (collective/individual), the type of fuel used in the heating system, and the age of the inhabitants for ET and the number of inhabitants per habitable floor area for EIU.

- For grid points with dominant industrial use, we only distinguish between a heated and non-heated part.

- For grid points with dominant uses "agriculture", "religious", "sport", "castle" and "non-heated", we do not consider for fractional use or behaviour.

$$
\begin{aligned}
& f_{\text {low }}=f_{\mathrm{ET}}^{\text {high }} p_{T-\text { low }}^{\text {Hight }}+\left(1-f_{\mathrm{ET}}^{\text {high }}\right) p_{T-\text { low }}^{\text {LowET }} \\
& f_{\text {med }}=f_{\mathrm{ET}}^{\text {high }} p_{T-\text { med }}^{\text {HighET }}+\left(1-f_{\mathrm{ET}}^{\text {high }}\right) p_{T-\text { med }}^{\text {LowET }} \\
& f_{\text {high }}=f_{\mathrm{ET}}^{\text {high }} p_{T-\text { high }}^{\text {HighET }}+\left(1-f_{\mathrm{ET}}^{\text {high }}\right) p_{T-\text { high }}^{\text {LowET }}
\end{aligned}
$$

The value for the internal heat release in the residential fraction of the buildings is initialised via the EIU indicator. We judge the differences between the values for high $\left(5 \mathrm{~W} \mathrm{~m}^{-2}\right)$ and low $\left(3 \mathrm{~W} \mathrm{~m}^{-2}\right)$ EIU to not be sufficiently large to justify the consideration of more fractional behaviours. Therefore, we apply the same value of the internal heat release in all three residential fractions. Nevertheless, the spatial variability of the internal heat release is taken into account by the maps of the EIU indicator (Fig. 4b). These are used to interpolate (Eq. 31) the average values of the nominative internal heat release $\left(\mathrm{QIN}_{\text {nom }}\right)$ for the high, medium and low EIU classes that are given in Table A4.

$$
\begin{aligned}
\mathrm{QIN}_{\text {nom }} & =f_{\mathrm{EIU}}^{\text {high }} \mathrm{QIN}_{\text {nom }}^{\text {HighEIU }}+f_{\mathrm{EIU}}^{\text {low }} \mathrm{QIN}_{\text {nom }}^{\text {LowEIU }} \\
& +\left(1-f_{\mathrm{EIU}}^{\text {low }}-f_{\mathrm{EIU}}^{\text {high }}\right) \mathrm{QIN}_{\text {nom }}^{\text {MedEIU }}
\end{aligned}
$$

We do not distinguish between specific types of ventilation and shading behaviours since, given the low prevalence of air conditioning, these are more relevant for indoor human thermal comfort then for building energy consumption.

\section{Evaluation of building energy consumption for the CAPITOUL campaign (Toulouse)}

In this section, we evaluate the spatio-temporal variability of building energy consumption simulated by our enhanced version of TEB. The evaluation is made for the CAPITOUL observation campaign (Masson et al., 2008) conducted between March 2004 and February 2005 for the agglomeration of Toulouse in southern France $\left(43.6^{\circ} \mathrm{N} ; 1.4^{\circ} \mathrm{E}\right)$. Various observations of the urban boundary layer were made. They include observations at a meteorological tower in the centre of Toulouse in 18.5 to $27.5 \mathrm{~m}$ above the average building height. We use the tower observations to force TEB in "Offline" Mode. An inventory of energy consumption was compiled by Pigeon et al. (2007) for the time period of the CAPITOUL campaign. In Sect. 4.1, we briefly describe the inventory and its uncertainties. We perform four simulations representing building use and human behaviour with different levels of complexity (Sect. 4.2). The results will be discussed in Sect. 4.3 and 4.4. In Sect. 4.5, we discuss the impact of using fractional building use and human behaviour on computation time.

\subsection{Inventory of building energy consumption}

The inventory of energy consumption covers both buildings and traffic. We focus on building energy consumption only. The inventory represents the energy consumption in a domain of $15 \mathrm{~km} \times 15 \mathrm{~km}$ covering the agglomeration of Toulouse. The underlying basic data are $10 \mathrm{~min}$ values of electricity consumption and daily values of gas consumption. These two energy sources cover about $85 \%$ of the building energy consumption. The contributions of other sources 
Table 1. Overview on the detail of representation of fractional building use and human behaviour for simulations in France.

\begin{tabular}{lrl}
\hline Dominant building use & Number of fractions & Type of fractional use and behaviour \\
\hline Residential & 6 & Non-heated fraction, commerce and office fraction, three design temperatures for heating \\
Office & 4 & Non-heated fraction, three design temperatures for heating and air conditioning \\
Commerce & 4 & Non-heated fraction, three design temperatures for heating and air conditioning \\
Education & 4 & Non-heated fraction, three design temperatures for heating \\
Public health & 4 & Non-heated fraction, three design temperatures for heating and air conditioning \\
Industry & 2 & Heated and non-heated fraction \\
Agriculture & 1 & Only main use \\
Religious & 1 & Only main use \\
Sport & 1 & Only main use \\
Castle & 1 & Only main use \\
Non-heated & 1 & Only main use \\
\hline
\end{tabular}

(e.g. wood, fuel) have been estimated by Pigeon et al. (2007) based on the INSEE-Census data on the prevailing fuel types used in heating systems and statistics on the mean annual energy consumption per heating system type available from the regional observatory for energy (Observatoire Régional de l'Energie en Midi-Pyrénées - OREMIP). We assume that the time dependency of energy consumption due to the other sources is proportional to the electricity and gas consumption. Uncertainties of the building energy consumption aggregated over the $15 \mathrm{~km} \times 15 \mathrm{~km}$ domain are mainly due to the spatial representativity of the gas consumption values, which is not precisely known, and the other sources. However, due to the low contribution of these other sources, we can assume that the domain-aggregated energy consumption is accurate to $\sim 15 \%$. There are no large industrial or agricultural energy consumers in the domain of investigation. Most of the energy is thus consumed inside residential, office and commercial buildings.

We spatially disaggregate the daily values of energy consumption to a grid of $250 \mathrm{~m} \times 250 \mathrm{~m}$ resolution following a very similar methodology than Pigeon et al. (2007). However, we use the total floor area instead of the building density as spatial weight to account for the fact that, on average, higher buildings consume more energy than lower buildings. The spatially disaggregated building energy consumption can be highly uncertain at single grid points, since we do not consider the building construction period or use, which are known to strongly influence building energy consumption.

We do not investigate sub-daily energy consumption as the gas consumption, which is the largest contributor during the heating season, is only available on daily basis.

\subsection{Model set-up}

TEB is the component of the SURFEX for urban areas. The purely vegetated part of the domain (only a few grid points) is simulated with the natural surface parametrisation ISBA (Noilhan and Planton, 1989), and the water surfaces (few small lakes and Garonne river) with the lake parametrisa- tion FLAKE (Mironov et al., 2010). Due to the choice of the offline approach, ruling out any effects of advection, the ISBA and FLAKE results can be expected to have no relevant influence on the model results presented here. Nevertheless, within the urbanised areas, the fraction of urban vegetation (e.g. gardens, parks, street trees) is considered in TEB following the methodology of Lemonsu et al. (2012). The vertical distribution of air temperature, humidity, wind speed and turbulent kinetic energy within the street canyon is taken into account (Hamdi and Masson, 2008). The road directions are assumed to be uniform. The convective exchange coefficients are calculated using the "DOE-2" option implemented by Pigeon et al. (2014). The aerodynamic roughness length is assumed to be the building height divided by 10 . The roughness length for scalar quantities is calculated following Kanda et al. (2007).

The domain of investigation is the same as for the spatially disaggregated inventory of energy consumption.

\subsubsection{Meteorological forcing}

The TEB simulation is conducted in "offline" Mode using $30 \mathrm{~min}$ values of air temperature, specific humidity, wind speed, direct and diffuse shortwave radiation, long-wave radiation, as well the rainfall and snowfall rate measured at the meteorological tower close to the centre of Toulouse as forcing. The wind direction is not relevant for this "offline" application. As the mast is located in the centre of the city, it includes urban effects like the urban heat island, which might reduce (increase) the energy consumption for heating (air conditioning). The same meteorological forcing is applied over the entire domain of investigation. Therefore, the air temperature of the forcing might be too high in the regions located in the suburban areas of Toulouse. However, as a large part of the heated floor area is located close to the city centre, the domain-aggregated energy demand might not be strongly influenced by this approximation. 
(a)

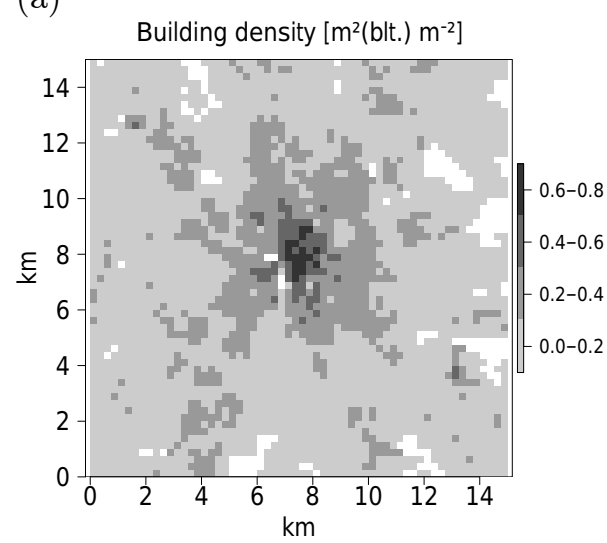

(c)

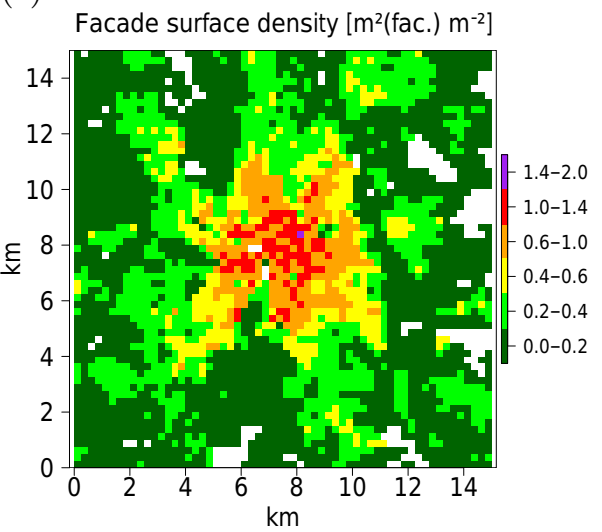

(b)

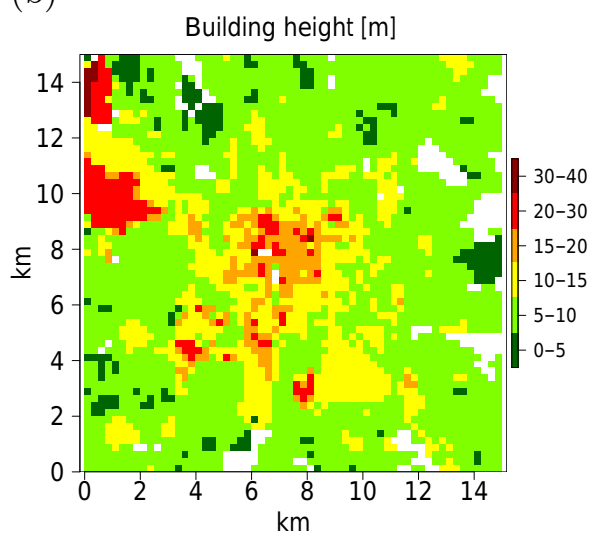

(d)

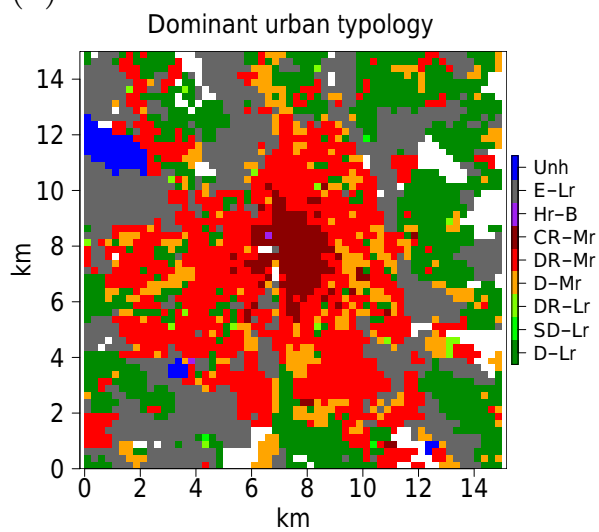

Figure 5. Urban morphology at a spatial resolution of $250 \mathrm{~m} \times 250 \mathrm{~m}$ for the agglomeration of Toulouse. The prevailing dominant urban typologies are detached low rise (D-Lr), semi-detached low rise (SD-Lr), discontinuous rows of low rise (DR-Lr), detached mid-rise (D-Mr), discontinuous rows of mid-rise (DR-Mr), continuous rows of mid-rise (CR-Mr), high-rise building (Hr-B), extended low-rise (E-Lr) and unheated buildings (Unh).

\subsubsection{Urban morphology and building architecture}

Data related to urban morphology and building architecture is taken from the MApUCE database, which provides information on urban morphology, architecture and behaviours for 80 French cities. The TEB input parameters related to urban morphology (e.g. building density, building height) have been calculated based on the information on building geometry included in the IGN-BDTOPO. The parameters related to building architecture (e.g. roof albedo) are initialised via the architectural database compiled by Tornay et al. (2017). The urban vegetation has been retrieved via satellite images (Crombette et al., 2014). In Fig. 5, we display the most relevant elements of the urban morphology for the domain of investigation. The building use is displayed in Fig. 3. The centre of Toulouse is characterised by a relatively small domain of about $2 \mathrm{~km} \times 2 \mathrm{~km}$ with a building density above 0.4 (Fig. 5a), building heights between 15 and $25 \mathrm{~m}$ (Fig. 5b) and a façade surface density above 1 (Fig. 5c). The dominant urban typology of this area is "continuous row of mid-rise"
(Fig. 5d). The remaining part of the domain is less densely built.

There are inconsistencies in the dates of our various input data (e.g. 2014 for the IGN-BDTOPO, 2011 for the INSEECensus) and the date of the CAPITOUL campaign (20042005). However, the change in the number of inhabitants within the domain of investigation between 2004 and 2014 is only about $10 \%$ and therefore of a similar magnitude as the uncertainty of the inventory on building energy consumption.

\subsubsection{Model experiments}

We perform a total of four simulations in order to test the influence of the behaviour-related input parameters on the simulated building energy consumption.

- DEF: "default" behaviour-related input parameters. Independently of building use or behavioural indicators, all buildings are heated to $19^{\circ} \mathrm{C}$ and air conditioned to $27^{\circ} \mathrm{C}$. The internal heat release is $5 \mathrm{~W} \mathrm{~m}^{-2}$, and there is neither ventilation nor shading. This would be a typ- 
(a) $\mathrm{DEF}$

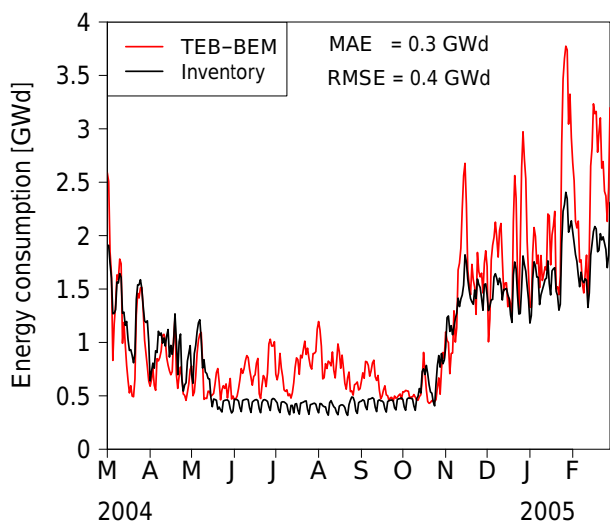

(c) SIX

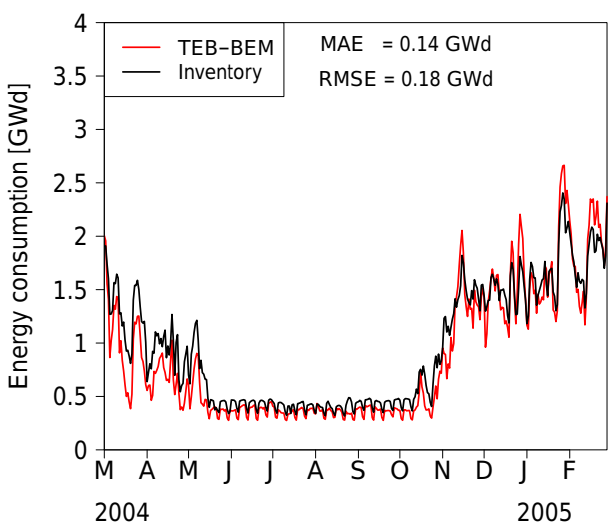

(b) DOM

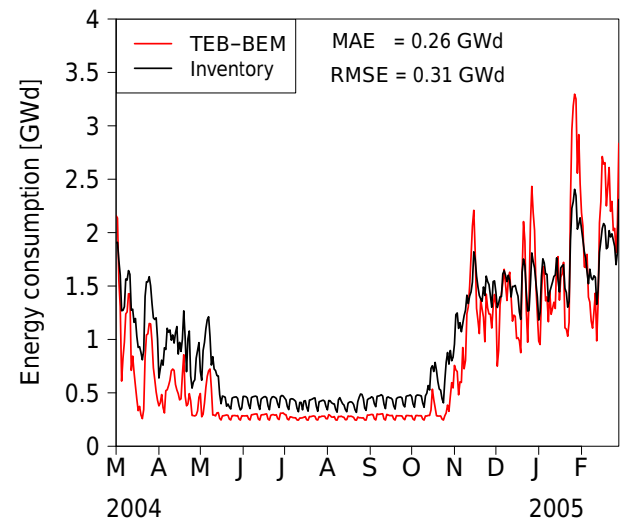

(d) MAP

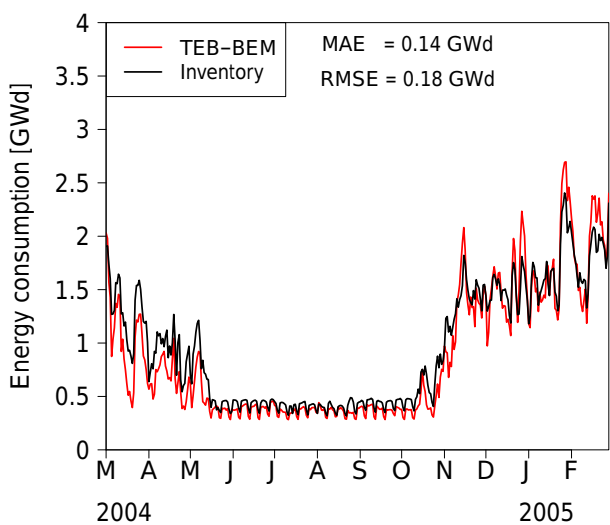

Figure 6. Simulated and observed time series of daily values of building energy consumption aggregated over the agglomeration of Toulouse for (a) uniform default behaviours (DEF), (b) behaviours assigned as a function of the dominant building use (DOM), (c) six uses and behaviours as described in Sect. 3.5, but with neutral behavioural indicators (SIX) and (d) six uses and behaviours and maps of behavioural indicators (MAP).

ical model configuration in cases where the modeller lacks specific knowledge of building use and human behaviour.

- DOM: behaviour-related input parameters are assigned as a function of the "dominant" building use (Tables A3, A4, A5). The design temperature for heating in the residential buildings corresponds to the arithmetic average between the values for high and low ET, the internal heat release in the residential buildings to the values for medium EIU. No fractional building use or human behaviour is considered.

- SIX: model configuration with six fractional uses and behaviours as described in Sect. 3.5, but with all behavioural indicators set to their "neutral" value. These are by definition of the behavioural indicators $f_{\mathrm{ET}}^{\text {high }}=$ 0.5 and $f_{\mathrm{EIU}}^{\text {high }}=0.25 ; f_{\mathrm{EIU}}^{\text {low }}=0.25$.
- MAP: model configuration for France as described in Sect. 3.5. The six most important fractional uses and behaviours are distinguished and the input parameters related to heating and internal heat release are initialised using the maps of the behavioural indicators (e.g. Fig. 4).

The comparison between the four model configurations indicates the degree to which the more complex representation of human behaviours improves the simulated building energy consumption.

\subsection{Domain-aggregated building energy consumption}

In Fig. 6, we display the time series of the simulated and observed daily values of domain-aggregated building energy consumption in gigawatt day (GWd). One gigawatt corresponds to the typical power of a nuclear or conventional power plant. To objectively quantify the influence of the 
more complex representation of human behaviour, we also calculate the mean absolute error (MAE) and the root mean square error (RMSE) of the daily energy consumption values.

During the warm season (mid-May to end of October), the inventory values are lowest $(\sim 0.4 \mathrm{GWd})$ and vary only slightly in time. The lack of dependence of energy consumption on air temperature indicates that air conditioning plays only a minor role. Energy consumption is mainly due to the use of electrical appliances. There is a weak weekly cycle, which is due to the closed shops on Sunday and the vacancy of offices on both Saturday and Sunday. During the cold season, due to the prevalence of heating, energy consumption increases strongly and is very sensitive to air temperature. For example, there is a marked increase of energy consumption to above $2 \mathrm{GWd}$ during a cold spell at the end of January.

The analysis of the four model experiments described in Sect. 4.2.3 indicates that a more complex representation of human behaviour enhances the simulated time series of building energy consumption. For DEF (Fig. 6a), the building energy consumption is overestimated during the warm season, since all buildings are air conditioned, which is not the case in reality. During the heating season, the building energy consumption is too sensitive to air temperature. For example, there is a strong overestimation of energy consumption during the cold wave at the end of January. This is due to the overestimation of the heated floor area, since for DEF all buildings are heated to $19^{\circ} \mathrm{C}$. The results for DEF indicate that large uncertainties of the building energy consumption might occur if no details on building use and human behaviour are taken into account.

Assigning the behaviour-related input parameters as a function of the dominant building use (DOM; Fig. 6b) improves the results. For example, the increase of energy consumption during warm periods is no longer simulated, since the residential buildings are no longer air conditioned. However, the sensitivity of the building energy consumption to air temperature is still too high. The main reason for this is that, in the real city, not all buildings are heated to the same temperature. Therefore, compared to the MAP configuration (Fig. 6d), less heating is required during the transition seasons since the fraction of buildings heated to relatively high design temperatures is not considered. During the coldest periods, the simulated building energy consumption is too high for DOM since the fraction of buildings heated to lower design temperatures and the commercial and office fractions are not considered.

The differences between the simulation with six fractional uses and behaviours, but neutral behavioural indicators (SIX; Fig. 6c) and the simulation with maps of the behavioural indicators (MAP; Fig. 6d) are small. This indicates that it is more important to account for the diverse range of heating design temperatures than for its detailed spatial variability. However, the maps of behavioural indicators might still improve the spatial pattern of simulated building energy demand.
The model experiments indicate that a rather detailed representation of the variety of building use and human behaviour is required to obtain good results for the time series of building energy consumption at the scale of an urban agglomeration. The RMSE and MAE decrease by a factor of 2 between the most detailed (MAP) and the simplest (DEF) representation of behaviours. For DEF, the magnitude of the simulated anthropogenic heat flux can be inaccurate up to a factor of 2. This could have adverse impacts, for example, on the simulated urban heat island when TEB is coupled to an atmospheric model.

Even for the most complex representation of behaviours, there are remaining uncertainties of the simulated building energy consumption, which must be kept in mind when applying the model to other urban agglomerations. These could be due to any of the following:

- renovation of buildings, which is taken into account only in a simplified way in the database on building architecture;

- the unknown capacity of the heating system. This might explain the overestimation of building energy consumption during the cold periods;

- neglecting ventilation during the cold season or overestimating solar heat gains, which might be responsible for the underestimation of building energy consumption in spring.

\subsection{Spatial distribution of building energy consumption}

We evaluate the spatial distribution of the anthropogenic heat flux due to building energy consumption simulated for the MAP model configuration against the spatially disaggregated inventory. The simulated and observed heat fluxes averaged over December, January, February (DJF) and June, July, August (JJA) are displayed in Fig. 7, with the spatial bias and RMSE for these time periods in Fig. 8. Building energy consumption is highest close to the city centre $\left(50\right.$ to $100 \mathrm{~W} \mathrm{~m}^{-2}$ in DJF and 20 to $50 \mathrm{Wm}^{-2}$ in JJA) and decreases towards the outskirts of the city. This spatial distribution is mainly consistent with the distribution of building density, building height and façade surface density (Fig. 5).

TEB provides a good representation of the spatial pattern of building energy consumption during both seasons. For DJF, there are areas with considerable biases, which are mainly due to the spatial distribution of the dominant building construction period (not shown). For example, the area south-east of the city centre is characterised by post-war buildings, which are known to be large consumers for heating energy. In this area, it is plausible that the simulated building energy consumption is larger than the inventory, since TEB takes into account for the influence of the construction period on construction materials, whereas the construction period has not been considered for the spatial disaggregation 
(a)

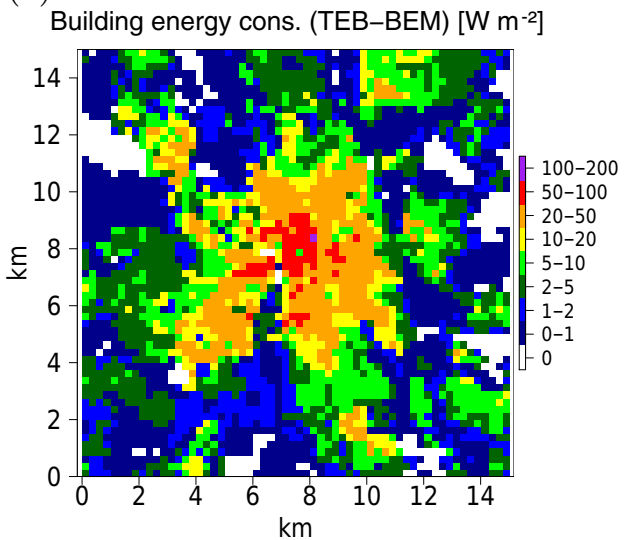

(c)

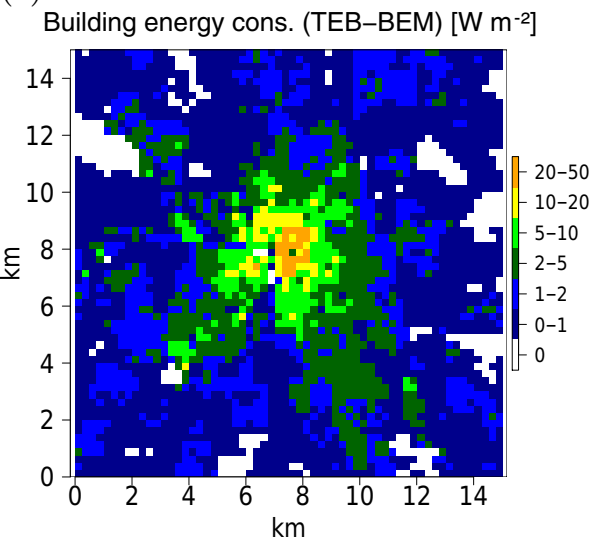

(b)

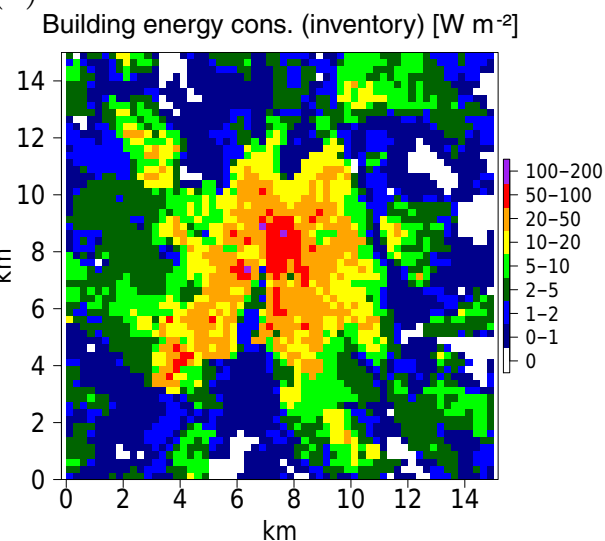

(d)

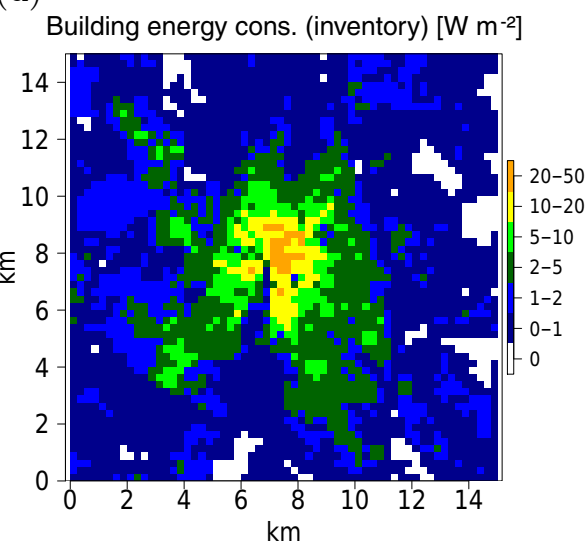

Figure 7. Anthropogenic heat flux due to building energy consumption in the agglomeration of Toulouse simulated for the MAP model configuration. (a) TEB results averaged over December, January and February (DJF); (b) same as (a), but spatially disaggregated inventory; (c, d) same as (a, b), but for June, July and August (JJA). The horizontal resolution is $250 \mathrm{~m} \times 250 \mathrm{~m}$.

of the energy consumption values in the inventory. For JJA, the values for the bias and RMSE are quite low. This is no surprise, since there is no heating, which is the main source of uncertainty for building energy consumption.

The evaluation of the spatial distribution of building energy consumption shows that the general pattern is represented well and the main differences between the TEB results and the inventory are not necessarily due to TEB shortcomings. Nevertheless, during the heating season, relatively large uncertainties of the simulated building energy demand remain at some grid points. Improved inventories are therefore required in order to further constrain the simulated building energy consumption.

\subsection{Influence of fractional behaviour on computation time}

The use of fractional behaviour leads to an increase of computation time. For the MAP simulation (six fractional behaviours), the wall clock time is increased by a factor of 1.95 compared to the DEF simulation (one building use and be- haviour). Our approach is therefore about a factor of 3 faster than using six tiles for the entire TEB scheme, which would increase the computation time by about a factor of 6 . However, it has to be kept in mind that computation time is very specific to the model set-up, application and computer. The simulations were performed using mpi on three Intel Core i7-2920XM CPU $(2.50 \mathrm{GHz})$ processors of a notebook with a Linux operating system. Different results for the computational performance might be obtained for other applications of TEB or on a different computer.

\section{Conclusions}

In this article, we presented how we enhance the Town Energy Balance TEB in order to take into account fractional building use and human behaviour, and how we deal with behaviours like heating, air conditioning, ventilation and shading. These can influence the building energy consumption, which can in turn be an important contributor to the anthropogenic heat flux. We show how we determine 
(a)

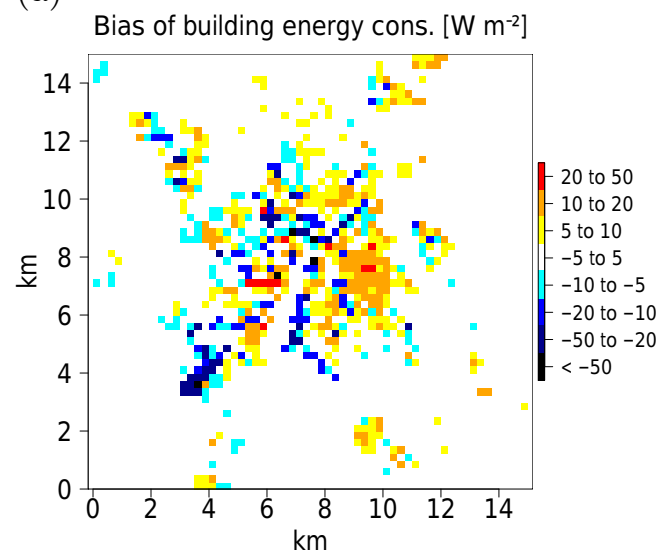

(c)

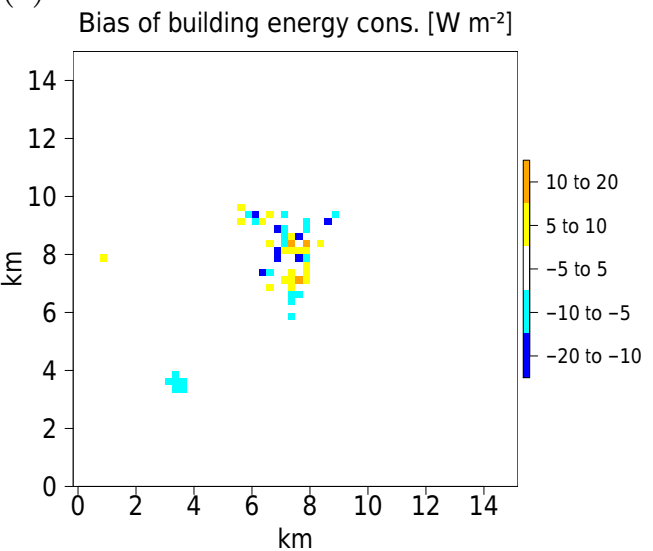

(b)

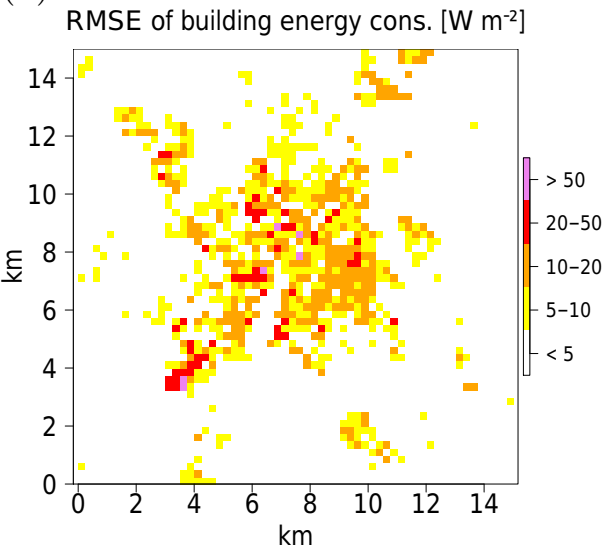

(d)

RMSE of building energy cons. [W $\left.\mathrm{m}^{-2}\right]$

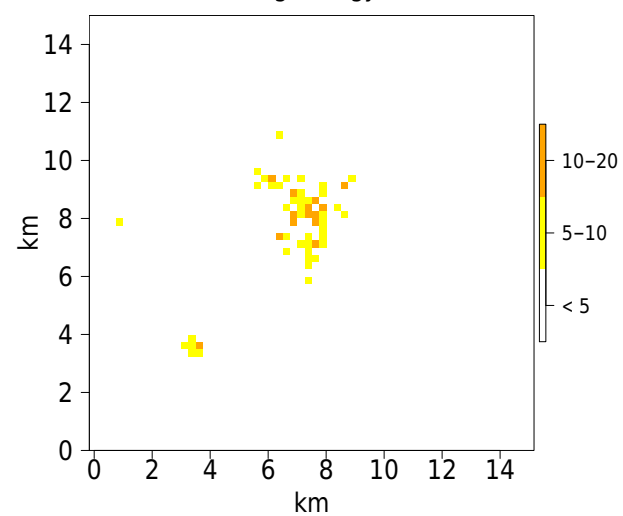

Figure 8. Evaluation of the spatio-temporal variability of simulated building energy consumption in the agglomeration of Toulouse for the MAP model configuration. (a) Bias for DJF, (b) root mean square error (RMSE) of the daily values for DJF, (c, d) same as (a, b), but for JJA. The horizontal resolution is $250 \mathrm{~m} \times 250 \mathrm{~m}$.

and initialise behaviour-related input parameters of TEB for France by combining information available from administrative datasets and surveys. We evaluated the enhanced version of TEB for the CAPITOUL campaign and demonstrated that a more detailed representation of building use and human behaviours improves the spatio-temporal variability of the simulated building energy consumption.

Future work on human behaviour-related aspects in TEB is needed to address two main issues.

- First, the described model configuration for France must be further evaluated and improved. This has been limited by the availability of data on building energy consumption. Additional data is becoming available thanks to open data policies. An evaluation for a variety of French cities could reveal potential shortcomings, such as the neglect of residential air conditioning or the neglect of secondary residences in regions with a lot of tourism. The climatic differences between northern and southern France might also reveal shortcomings, since we could only evaluate the model for a city in southern France.

- Second, additional work is required in order to obtain information on human behaviour in other regions of the world. While the model developments and parametrisations presented in this article remain valid, substantial changes of the model configuration will have to be made in subtropical or tropical regions, where heating plays little to no role, but the practices of the inhabitants concerning ventilation and air conditioning need to be considered in order to correctly simulate the building energy demand. Data on building use, equipment and human behaviour might be derived from inventories, sector-wide energy consumption data, OpenStreetMap or surveys.

The TEB developments we describe in this article lay the groundwork for simulations of urban climate coupled to building energy consumption. In future studies, the feedbacks between the building energy consumption and the ur- 
ban climate should be investigated in simulations where TEB is coupled to an atmospheric model. Especially for the winter season, it would be useful to quantify the feedbacks between heating energy consumption and the urban heat island, since this has not been done much. The building energy consumption is often related to emissions of pollutants and $\mathrm{CO}_{2}$. These emissions could be parametrised in the atmospheric models as a function of the simulated building energy consumption and the type of heating and air conditioning system. The impact of climate change mitigation and adaptation measures such as green and white roofs on both the urban climate and building energy consumption should be investigated in order to quantify their potential in different parts of the world.
Code availability. The TEB code is available in open source via the surface modelling platform SURFEX (http://www. cnrm-game-meteo.fr/surfex/). It is updated relatively infrequently (every 3 to 6 months). The developments presented here are not yet included in the latest version. However, their inclusion is planned. In the meantime, the routines modified with respect to SURFEX v.8.0 as well as the run directories of the model experiments described in Sect. 4.2 .3 can be retrieved via https://zenodo.org/record/818632 (Schoetter et al., 2017, https://doi.org/10.5281/zenodo.818632).

Data availability. The MApUCE database describing the tissue of about 80 urban agglomerations in France can be visualised (http: //mapuce.orbisgis.org/). The underlying data are partly available on request. 


\section{Appendix A: Representation of human behaviours in TEB}

In this section, we describe how we represent different human behaviours in TEB. Due to the non-linearity of most involved processes, all model equations presented in this appendix are solved separately for each fractional building use and behaviour.

\section{A1 Schedules of building occupation}

Human behaviours such as the adjustment of the design temperature for heating and air conditioning, opening windows, or the use of shading devices are related to the presence of humans and their activity. For each building use, we therefore define a fractional building occupation $\left(f_{\text {occ }}\right)$ with a predefined diurnal cycle (Table A1) that might be different for weekdays (Monday to Friday), Saturday and Sunday. The distinction between Saturday and Sunday is motivated mainly by the fact that commercial buildings in France usually open on Saturday, but only rarely on Sunday. The last column in Table A1 defines the "night", which is the time period when the inhabitants of residential buildings are sleeping and when buildings with other uses are inactive. The term "night" is used here in the behavioural sense (e.g. the time when people are asleep for residential buildings, the inactive period for office buildings) and not in the astronomical sense. The values of $f_{\text {occ }}$ as a function of the schedules are given in Table A2. For the residential buildings, they are adapted from Wilke (2013), who analysed a survey on the time use of 15000 individuals in France. For non-residential buildings, the values are based on general knowledge concerning office hours, school hours and so on in France. Given the lack of robust information and the relatively low importance, we do not consider occupation schedules of buildings with "agricultural", "industry", "religious", "sport", "castle" and "non-heated" use.

In order to avoid abrupt changes in building occupation, we apply a moving average in time on the values in Table A2. The averaging window is $1 \mathrm{~h}$.

We assume that no modification of the state of the building is possible for the vacant part of the buildings, or at night. An exception are actively managed buildings (e.g. those with automatic ventilation), which have already been implemented by Bueno et al. (2012) in TEB; such buildings are not considered here.

Given the importance of summer holidays in France, we modulate the building occupation for some uses during the summer holiday period. For educational (office) buildings, we reduce the building occupation by $90 \%$ (25\%) between the beginning of July and the end of August. The modulation factor for offices is adapted from Vorger (2014). For commercial and public health buildings we reduce the building occupation by $25 \%$ between the end of July and the end of August. We do not modulate building occupation for resi-
Table A1. Definition of the schedules used to assign the building occupation. A total of four time intervals per day ( $S 1$ to $S 4$ ) are considered. The time period defined for $S 4$ corresponds to the "night". The values are in solar time. In France, solar time is $1 \mathrm{~h}(2 \mathrm{~h})$ earlier than local time in winter (daylight savings time).

\begin{tabular}{lrrrr}
\hline Building use & $S 1[\mathrm{~h}]$ & $S 2[\mathrm{~h}]$ & $S 3[\mathrm{~h}]$ & $S 4[\mathrm{~h}]$ \\
\hline Residential & $5-7$ & $7-16$ & $16-23$ & $23-5$ \\
\hline Office & $7-11$ & $11-16$ & $16-19$ & $19-7$ \\
\hline Commerce & $8-11$ & $11-14$ & $14-19$ & $19-8$ \\
\hline Education & $7-11$ & $11-16$ & $16-19$ & $19-7$ \\
\hline Public health & $7-11$ & $11-16$ & $16-19$ & $19-7$ \\
\hline
\end{tabular}

dential buildings, since the part of people leaving for holidays may be compensated by the part of people not working, but not leaving for holidays. The consideration of holidays is very specific to France and will have to be adapted for other countries.

\section{A2 Design temperature for heating and air conditioning}

We consider that the design temperature for heating $(\mathrm{TH})$ and air conditioning (TC) might differ between occupied (occ) and vacant (vac) buildings and during the day (day) and night (nig). The design temperatures are modulated with the building occupation and the day/night switch to obtain the current design temperature for heating $\left(\mathrm{TH}_{\mathrm{cur}}\right.$, Eq. A1) and air conditioning $\left(\mathrm{TC}_{\mathrm{cur}}, \mathrm{Eq}\right.$. A2). This approach ensures that variations in the design temperature are smooth and thus do not create unrealistic variations of grid-point-scale building energy consumption.

$$
\begin{aligned}
\mathrm{TH}_{\mathrm{cur}} & =f_{\text {nig }}\left(f_{\mathrm{occ}} \mathrm{TH}_{\mathrm{occ}}^{\mathrm{nig}}+\left(1-f_{\mathrm{occ}}\right) \mathrm{TH}_{\mathrm{vac}}^{\mathrm{nig}}\right) \\
& +\left(1-f_{\text {nig }}\right)\left(f_{\mathrm{occ}} \mathrm{TH}_{\mathrm{occ}}^{\mathrm{day}}+\left(1-f_{\mathrm{occ}}\right) \mathrm{TH}_{\mathrm{vac}}^{\mathrm{day}}\right) \\
\mathrm{TC}_{\mathrm{cur}} & =f_{\text {nig }}\left(f_{\mathrm{occ}} \mathrm{TC}_{\mathrm{occ}}^{\text {nig }}+\left(1-f_{\mathrm{occ}}\right) \mathrm{TC}_{\mathrm{vac}}^{\mathrm{nig}}\right) \\
& +\left(1-f_{\text {nig }}\right)\left(f_{\mathrm{occ}} \mathrm{TC}_{\mathrm{occ}}^{\mathrm{day}}+\left(1-f_{\mathrm{occ}}\right) \mathrm{TC}_{\mathrm{vac}}^{\mathrm{day}}\right)
\end{aligned}
$$

The values for the heating and cooling design temperature are given in Table A3.

\section{A3 Internal heat release}

For the internal heat release, we consider a nominative value $\left(\mathrm{QIN}_{\text {nom }}\right)$, which corresponds to situations when the building is occupied during the day. This nominative value is modulated with the factor $M_{\text {vac }}\left(M_{\text {nig }}\right)$ when the building is vacant (at night). The current internal heat release $\left(\mathrm{QIN}_{\text {cur }}\right)$ is then calculated following Eq. (A3).

$$
\begin{aligned}
\mathrm{QIN}_{\text {cur }} & =f_{\text {nig }}\left(\mathrm{QIN}_{\text {nom }} M_{\text {nig }}\right)+\left(1-f_{\text {nig }}\right)\left(f_{\text {occ }} \mathrm{QIN}_{\text {nom }}\right. \\
& \left.+\left(1-f_{\text {occ }}\right) \mathrm{QIN}_{\text {nom }} M_{\text {vac }}\right)
\end{aligned}
$$

The values for the internal heat release are given in Table A4. 
Table A2. Fractional building occupation $\left(f_{\text {occ }}\right)$ as a function of building use, time of day, and day of the week. The distinguished time intervals are Monday to Friday (MF), Saturday (SA) and Sunday (SU). The schedules $S 1$ to $S 4$ are defined in Table A1. We do not consider schedules of building occupation for the building uses "industry", "agriculture", "religious", "sport", "castle" and "non heated".

\begin{tabular}{lrrrrrrrrrrrr}
\hline Building use & $\mathrm{MF}_{S 1}$ & $\mathrm{MF}_{S 2}$ & $\mathrm{MF}_{S 3}$ & $\mathrm{MF}_{S 4}$ & $\mathrm{SA}_{S 1}$ & $\mathrm{SA}_{S 2}$ & $\mathrm{SA}_{S 3}$ & $\mathrm{SA}_{S 4}$ & $\mathrm{SU}_{S 1}$ & $\mathrm{SU}_{S 2}$ & $\mathrm{SU}_{S 3}$ & $\mathrm{SU}_{S 4}$ \\
\hline Residential & 0.90 & 0.40 & 0.75 & 0.90 & 0.85 & 0.65 & 0.75 & 0.85 & 0.85 & 0.65 & 0.75 & 0.85 \\
\hline Office & 0.95 & 0.95 & 0.25 & 0.01 & 0.10 & 0.10 & 0.01 & 0.01 & 0.05 & 0.05 & 0.01 & 0.01 \\
\hline Commerce & 0.95 & 0.95 & 0.80 & 0.00 & 0.90 & 0.75 & 0.75 & 0.00 & 0.10 & 0.10 & 0.05 & 0.00 \\
\hline Education & 0.95 & 0.70 & 0.30 & 0.00 & 0.50 & 0.30 & 0.20 & 0.00 & 0.05 & 0.05 & 0.0 & 0.00 \\
\hline Public health & 0.95 & 0.95 & 0.70 & 0.50 & 0.70 & 0.70 & 0.60 & 0.40 & 0.50 & 0.50 & 0.40 & 0.30 \\
\hline
\end{tabular}

Table A3. Design temperature for heating (TH) and air conditioning (TC) as well as non-heated fraction $\left(f_{\mathrm{NH}}\right)$ of the building. The values for the "night" are assumed to be equal to the values during the day when the building is vacant. A "_" indicates that no heating or air conditioning is taken into account. For the residential buildings, the values are based on the ENERGIHAB survey for the two classes of the efficiency tendency (ET) indicator defined by Bourgeois et al. (2017).

\begin{tabular}{lrrrrr}
\hline Building use & $\mathrm{TH}_{\mathrm{occ}}^{\mathrm{day}}\left[{ }^{\circ} \mathrm{C}\right]$ & $\mathrm{TH}_{\mathrm{vac}}^{\mathrm{day}}\left[{ }^{\circ} \mathrm{C}\right]$ & $\mathrm{TC}_{\mathrm{occ}}^{\mathrm{day}}\left[{ }^{\circ} \mathrm{C}\right]$ & $\mathrm{TC}_{\mathrm{vac}}^{\mathrm{day}}\left[{ }^{\circ} \mathrm{C}\right]$ & $f_{\mathrm{NH}}$ \\
\hline Individual housing, high ET & 18.6 & 17.6 & - & - & 0.20 \\
Individual housing, low ET & 22.0 & 22.0 & - & - & 0.10 \\
Collective housing, high ET & 18.4 & 17.4 & - & - & 0.30 \\
Collective housing, low ET & 22.3 & 22.3 & - & - & 0.15 \\
Office & 21 & 20 & 28 & 33 & 0.2 \\
Commerce & 21 & 20 & 28 & 33 & 0.2 \\
Education & 21 & 20 & - & - & 0.2 \\
Public health & 21 & 20 & 28 & 33 & 0.2 \\
Industry & 20 & 20 & - & - & 0.95 \\
Agriculture & - & - & - & - & 0.0 \\
Religious & 8 & 8 & - & - & 0.0 \\
Sport & 8 & 8 & - & - & 0.0 \\
Castle & 16 & 16 & - & - & 0.0 \\
Non-heated & - & - & - & - & 0.0 \\
\hline
\end{tabular}

\section{A4 Shading}

Shading is only possible for buildings equipped with shading elements. Here we describe the treatment of shading for such buildings.

Human behaviour related to shading depends primarily on shortwave radiation and secondarily on indoor air temperature (Raja et al., 2001; Haldi and Robinson, 2010). These meteorological parameters are particularly important in office buildings, whereas in residential buildings nonmeteorological parameters like privacy or security can also influence shading (Vorger, 2014). Since we do not take the drivers of shading, such as privacy, into account, we calculate the fraction of closed shading elements as a function of the status of building occupation and the meteorological conditions, mainly the shortwave radiation received by the walls. The following model input parameters related to shading are specified for each building use
- the fraction of shading elements closed when the building is vacant $\left(f_{\text {shade }}^{\text {vac }}\right)$;

- the fraction of shading elements closed during the night $\left(f_{\text {shade }}^{\text {nig }}\right)$;

- the fraction of shading elements adapted as a function of shortwave radiation $\left(f_{\text {shade }}^{\mathrm{sw}}\right)$.

The values of the input parameters are given in Table A5. Based on these, and the status of building occupation, we first calculate the fraction of closed shading elements independently of the current meteorological conditions ( $f_{\text {shade }}^{\text {ind }}$; Eq. A4).

$f_{\text {shade }}^{\text {ind }}=f_{\text {nig }} f_{\text {shade }}^{\text {nig }}+\left(1-f_{\text {nig }}\right)\left(\left(1-f_{\text {occ }}\right) f_{\text {shade }}^{\text {vac }} \mathrm{LS}_{\text {vac }}\right)$

In Eq. (A4), the shading for vacant buildings is only applied when the indoor air temperature was above $23^{\circ} \mathrm{C}$ at the end of the night ( $\mathrm{LS}_{\mathrm{vac}}$-switch). This parametrises, in a simple way, the fact that people reduce (increase) solar heat gains during the warm (cold) season. 
Table A4. Nominative value of the internal heat release $\left(\mathrm{QIN}_{\mathrm{nom}}\right)$, modulation factor for periods when the building is vacant $\left(M_{\mathrm{vac}}\right)$ and during the night $\left(M_{\text {nig }}\right)$ and radiative part of internal heat releases $\left(f_{\text {rad }}\right)$. For the residential buildings, the values for QIN ${ }_{\text {nom }}$ are based on the ENERGIHAB and ENL surveys for the three classes of the equipment-intensity-of-use (EIU) indicator.

\begin{tabular}{lrrrr}
\hline Building use & QIN $_{\text {nom }}\left[\mathrm{W} \mathrm{m}^{-2}\right]$ & $M_{\text {vac }}$ & $M_{\text {nig }}$ & $f_{\text {rad }}$ \\
\hline Individual housing, high EIU & 5 & 1.0 & 0.5 & 0.2 \\
Individual housing, medium EIU & 4 & 1.0 & 0.5 & 0.2 \\
Individual housing, low EIU & 3 & 1.0 & 0.5 & 0.2 \\
Collective housing, high EIU & 5 & 1.0 & 0.5 & 0.2 \\
Collective housing, medium EIU & 4 & 1.0 & 0.5 & 0.2 \\
Collective housing, low EIU & 3 & 1.0 & 0.5 & 0.2 \\
Office & 15 & 0.4 & 0.4 & 0.4 \\
Commerce & 10 & 0.4 & 0.4 & 0.4 \\
Education & 10 & 0.4 & 0.4 & 0.2 \\
Public health & 10 & 0.4 & 0.4 & 0.2 \\
Industry & 5 & 1.0 & 1.0 & 0.2 \\
Agriculture & 1 & 1.0 & 1.0 & 0.2 \\
Religious & 1 & 1.0 & 1.0 & 0.2 \\
Sport & 1 & 1.0 & 1.0 & 0.2 \\
Castle & 1 & 1.0 & 1.0 & 0.2 \\
Non-heated & 0 & 1.0 & 1.0 & 0.2 \\
\hline
\end{tabular}

Second, we define a fraction of shading elements that can be adapted as a function of the current meteorological conditions. It is determined following Eq. (A5) based on the building occupation status and $f_{\text {shade }}^{\text {sw }}$.

$f_{\text {shade }}^{\text {adapt }}=\left(1-f_{\text {nig }}\right) f_{\text {occ }} f_{\text {shade }}^{\text {sw }}$

The fraction of shading elements currently closed ( $\left.f_{\text {shade }}^{\text {cur }}\right)$ is then calculated by combining $f_{\text {shade }}^{\text {ind }}$ and the fraction closed as a function of the current shortwave radiation received by the walls ( $\left.\mathrm{SW}_{\text {to wall }}\right)$ following Eq. (A6).

$$
f_{\text {shade }}^{\text {cur }}=f_{\text {shade }}^{\text {ind }}+f_{\text {shade }}^{\text {adapt }} \frac{1}{1+\exp \left(-0.05\left(\mathrm{SW}_{\text {to wall }}-\mathrm{SW}_{\text {th }}\right)\right)}
$$

The use of the logistic function in Eq. (A6) assures smooth variations in time for the fraction of closed shading elements. The default value of the threshold for shortwave radiation $\left(\mathrm{SW}_{\text {th }}\right)$ is set to $150 \mathrm{~W} \mathrm{~m}^{-2}$.

The computations of the solar radiation reflected, absorbed and transmitted by the windows with and without shading are made separately and are then weighted with $f_{\text {shade }}^{\text {cur }}$. This linearisation does not introduce large errors, as the processes involved are relatively linear.

\section{A5 Ventilation}

Human behaviour related to the ventilation of buildings depends on various meteorological and non-meteorological parameters. During the warm season, the air temperature inside and outside the building can be drivers for the use of ventilation in order to optimise thermal comfort (Roetzel et al., 2010; Fabi et al., 2013). However, other drivers for ventilation exist: for example, wind speed and precipitation (Roet- zel et al., 2010), noise (Fabi et al., 2013), safety issues, indoor $\mathrm{CO}_{2}$ concentration (Andersen et al., 2013) or indoor air quality (Fabi et al., 2013).

In the current version of TEB, we lack information on noise, safety issues or indoor air quality, and so we cannot take them into account. We therefore calculate the fraction of windows opened as a function of the building occupation status and the air temperature inside and outside of the building based on the following model input parameters:

- The fraction of windows opened when the building is vacant $\left(f_{\text {vent }}^{\text {vac }}\right)$.

- The fraction of windows opened during the night $\left(f_{\mathrm{vent}}^{\mathrm{nig}}\right)$.

- The fraction of windows opened during situations with heat stress $\left(f_{\text {vent }}^{\text {warm }}\right)$.

The values for the model input parameters related to ventilation are given in Table A5. Similar to our treatment of shading, we first calculate the fraction of open windows independently from the current meteorological conditions $\left(f_{\text {vent }}^{\text {ind }}\right)$ following Eq. (A7).

$f_{\text {vent }}^{\text {ind }}=f_{\text {nig }} f_{\text {vent }}^{\text {nig }} \mathrm{LV}_{\text {nig }}+\left(1-f_{\text {nig }}\right)\left(\left(1-f_{\text {occ }}\right) f_{\text {vent }}^{\text {vac }}\right)$

In Eq. (A7), ventilation during the night is only made if the indoor air temperature was above $23^{\circ} \mathrm{C}$ at the beginning of the night $\left(\mathrm{LV}_{\text {nig-switch}}\right.$. This parametrises the fact that during warm conditions, people might use ventilation at night.

The fraction of windows that may be opened as a function of the current meteorological conditions ( $f_{\text {vent }}^{\text {adapt }}$ ) is given by Eq. (A8) as a function of building occupation and day/night 
Table A5. Fraction of buildings for which ventilation $\left(f_{\text {vent }}\right)$ or shading $\left(f_{\text {shade }}\right)$ is applied during warm conditions (warm) or as a function of the shortwave radiation (sw), the night (nig) and when the building is vacant (vac). For the residential buildings, the values are based on the ENERGIHAB survey.

\begin{tabular}{lrrrrrr}
\hline Building use & $f_{\text {vent }}^{\text {warm }}$ & $f_{\text {vent }}^{\text {nig }}$ & $f_{\text {vent }}^{\text {vac }}$ & $f_{\text {shade }}^{\text {sw }}$ & $f_{\text {shade }}^{\text {nig }}$ & $f_{\text {shade }}^{\text {vac }}$ \\
\hline Individual housing & 0.71 & 0.60 & 0.0 & 0.82 & 0.60 & 1.0 \\
\hline Collective housing & 0.60 & 0.52 & 0.0 & 0.75 & 0.60 & 1.0 \\
\hline Education & 1.0 & 0.0 & 0.0 & 0.0 & 0.0 & 0.0 \\
\hline Other uses & 0.0 & 0.0 & 0.0 & 0.0 & 0.0 & 0.0 \\
\hline
\end{tabular}

Table A6. Conditional probability that a household will heat to the low, medium and high design temperature as a function of its efficiency tendency (ET) class (high or low). The conditional probabilities are derived from the ENERGIHAB survey, the values for the design temperature are given in Table A3.

\begin{tabular}{lrrr}
\hline Building use & $p_{T-\text { low }}$ & $p_{T-\text { med }}$ & $p_{T-\text { high }}$ \\
\hline Individual housing, high ET & 0.52 & 0.36 & 0.12 \\
\hline Individual housing, low ET & 0.19 & 0.36 & 0.45 \\
\hline Collective housing, high ET & 0.56 & 0.28 & 0.16 \\
\hline Collective housing, low ET & 0.19 & 0.29 & 0.52 \\
\hline
\end{tabular}

status and the fraction of windows that may be opened during situations with heat stress.

$f_{\text {vent }}^{\text {adapt }}=\left(1-f_{\text {nig }}\right) f_{\text {occ }} f_{\text {vent }}^{\text {warm }}$

The fraction of windows currently opened $\left(f_{\text {vent }}^{\text {cur }}\right)$ is the sum of $f_{\mathrm{vent}}^{\text {ind }}$ and the fraction, which is opened as a function of the current meteorological conditions (Eq. A9).

$$
\begin{aligned}
f_{\text {vent }}^{\text {cur }} & =f_{\text {vent }}^{\text {ind }}+f_{\text {vent }}^{\text {adapt }} \frac{1}{1+\exp \left(-\left(T_{\text {air }}^{\text {ind }}-\mathrm{TV}_{\text {th }}\right)\right)} \\
& \frac{1}{1+\exp \left(-\left(T_{\text {air }}^{\text {ind }}-T_{\text {air }}^{\text {can }}\right)\right)}
\end{aligned}
$$

In Eq. (A9), we assume a reasonable, but not perfect behaviour. People tend to open windows when the indoor air temperature is higher than the threshold $\mathrm{TV}_{\text {th }}$. We choose a value of $25^{\circ} \mathrm{C}$ for $\mathrm{TV}_{\text {th }}$, since heat stress is likely to occur for higher indoor air temperatures. Further, we assume that people tend to not open the windows when the air temperature in the street canyon is higher than the indoor air temperature. The use of the logistic function in Eq. (A9) ensures that there are no abrupt transitions of the fraction of open windows.

Ventilation during the cold season is not taken into account since the structural formulation of the building energy model excludes that heating and ventilation are taking place at the same time. Also the formulation of Eq. (A9) and particularly the choice of $\mathrm{TV}_{\mathrm{th}}=25^{\circ} \mathrm{C}$ make sure that the fraction of opened windows tends towards zero if the indoor air temperature is below $25^{\circ} \mathrm{C}$. The neglect of ventilation during the cold season might not lead to large uncertainties for noninsulated buildings, since heat conduction through the building envelope and infiltration is responsible for a large part of the heating energy demand. For modern buildings complying with rigorous thermal regulation standards, ventilation during the cold season might contribute to a larger extent to the heating energy demand. Further developments of TEB might therefore be required to take into account for ventilation during the cold season.

In order to calculate the air exchange rate due to ventilation (VENT, $\left[\mathrm{m}^{3} \mathrm{~m}(\mathrm{bld})^{-2} \mathrm{~s}^{-1}\right]$ ), we implement the formula for single-sided ventilation defined by the European directive prEN15242 (EC, 2006) given by Eq. (A10).

$$
\begin{aligned}
\text { VENT } & =0.5 f_{\text {vent }}^{\text {cur }} A_{\text {bld }}^{\text {win }} \\
& \sqrt{0.01+0.001 U^{2}+0.00525\left|T_{\text {air }}^{\text {ind }}-T_{\text {air }}^{\text {can }}\right|}
\end{aligned}
$$

This takes into account the ventilation due to the air temperature difference between indoor $\left(T_{\text {air }}^{\text {ind }}\right)$ and outdoor $\left(T_{\text {air }}^{\text {can }}\right)$ due to the stack effect and the forcing due to the wind in the street canyon $(U)$. $A_{\text {bld }}^{\text {win }}$ denotes the ratio between the glazed surface and the building footprint.

The value for the air exchange rate is multiplied by $f_{\text {vent }}^{\text {cur }}$ to consider for the fraction of windows opened. Contrary to shading, this linearisation introduces considerable uncertainties, since the processes related to ventilation are non-linear. However, if these uncertainties are judged as too important for the given application of TEB, it is possible to introduce more fractional behaviours in order to distinguish between different ventilation behaviours.

For the cases where shading is applied at the same time as ventilation, the air exchange rate due to ventilation is divided by a factor of 10. A more physically based calculation of the ventilation through closed shading elements is not possible at this time, given the large uncertainties related to the design of the shading elements, the opening angle of the window, and the building architecture. 


\section{A6 Air exchange rate due to infiltration}

In addition to the air exchange due to ventilation, there is air exchange between the interior and exterior due to small holes in the building envelope. This is referred to here as infiltration. It depends on the airtightness $\left(C_{\text {air }}\left[\mathrm{vol} \mathrm{h}^{-1}\right]\right)$ of the building and the meteorological conditions. Indeed, the infiltration is caused by pressure differences between the inside and outside. These are caused by differences between indoor and outdoor air temperature (stack effect) and the forcing due to wind (wind effect). Bueno et al. (2012) specify a fixed infiltration rate. However, this neglects the dependency of infiltration on the meteorological conditions. For this reason, we now prescribe the airtightness of the building as model input parameter and use the Alberta infiltration model (Wang et al., 2009) to calculate the air exchange rate due to infiltration as a function of the meteorological conditions. The contribution of the stack effect to infiltration $\left(I_{\text {stack }}\right)$ is given by Eq. (A11), and the contribution from the wind effect $\left(I_{\text {wind }}\right)$ by Eq. (A12). The total infiltration rate $\left(I_{\text {tot }}\right)$ is then the combination of the stack and wind effect (Eq. A13).

$$
\begin{aligned}
& I_{\text {stack }}=C_{\text {air }} F_{\text {stack }}\left(\rho g H_{\text {bld }} \frac{\left|T_{\text {air }}^{\text {can }}-T_{\text {air }}^{\text {ind }}\right|}{T_{\text {air }}^{\text {ind }}}\right)^{\alpha} \\
& I_{\text {wind }}=C_{\text {air }} F_{\text {wind }}\left(0.5 \rho U^{2}\right)^{\alpha} \\
& I_{\text {tot }}=\left(I_{\text {stack }} \frac{1}{\alpha}+I_{\text {wind }^{\alpha}} \frac{1}{\alpha}+\beta\left(I_{\text {stack }} I_{\text {wind }}\right)^{\frac{1}{2 \alpha}}\right)^{\alpha}
\end{aligned}
$$

The density of air in the street canyon is denoted by $\rho$, the building height by $H_{\text {bld }} . g$ is the acceleration due to gravity, $U$ the wind speed in the street canyon. The value for the flow exponent $\alpha$ is set to 0.66 , which is a typical value for infiltration flow that lies in between fully laminar (1.0) and fully turbulent flow (0.5) (Wang et al., 2009). The empirical constant $\beta$ is set to -0.33 , similar to Wang et al. (2009).

The stack factor $\left(F_{\text {stack }}\right)$ is calculated based on Walker and Wilson (1998) (Eqs. A14 to A16).

$$
\begin{aligned}
& F_{\text {stack }}=F+\left(\frac{1+R \alpha}{1+\alpha}\right)\left(0.5-0.5(M)^{1.2}\right)^{(1+\alpha)} \\
& M=\min \left(1.0, \frac{(X+Y(2 \alpha+1))^{2}}{2-R}\right) \\
& F=\alpha Y\left(H_{\text {flue }}-1.0\right)^{\left(\alpha-\frac{1}{3}\right)}\left(1-\frac{\left(3(C-X)^{2} R^{(1-\alpha)}\right.}{2\left(H_{\text {flue }}+1\right)}\right) \\
& C=R+\frac{2(1-R-Y)}{1+\alpha}-2 Y\left(H_{\text {flue }}-1.0\right)^{\alpha}
\end{aligned}
$$

The values of $R$ and $X$ are set to 0.0, which assumes that there is no leakage through the roof, except through the flue. For the flue fraction $(Y)$ and the normalised flue height $\left(H_{\text {flue }}\right)$ we choose the typical values of 0.2 and 1.5 (Walker and Wilson, 1998).
The wind factor $\left(F_{\text {wind }}\right)$ is also calculated following Walker and Wilson (1998) (Eqs. A18 and A19).

$$
\begin{aligned}
& F_{\text {wind }}=0.19(2-\alpha)\left(1-(0.5(X+R))^{(1.5-Y)}\right) \\
& \quad-0.25 Y\left(J-2.0 Y J^{4}\right) \\
& J=0.5(X+R+2 Y)
\end{aligned}
$$

In order to test the influence of air exchange between indoor and outdoor due to infiltration on the heating energy demand, we perform a simulation similar to the MAP experiment (Sect. 4.2.3), but assuming zero infiltration. During the coldest periods of the year, the infiltration is responsible for about one-third of the heating energy demand (not shown), which is a reasonable value. TEB overestimates the sensitivity of the heating energy demand to air temperature for this "no infiltration" experiment. This shows that the too high values for this sensitivity found in the DEF and DOM experiments cannot be explained by a too strong dependency of infiltration on air temperature.

\section{Appendix B: Definition of surface ratios and view factors}

We describe here how the surface ratios and view factors are calculated based on model input parameters.

\section{B1 Surface ratios}

The ratios between the roof $\left(A_{\text {bld }}^{\text {roof }}\right)$ and floor $\left(A_{\text {bld }}^{\text {floor }}\right)$ surface and the building ground surface are 1.0 by definition (Eqs. B1 and $\mathrm{B} 2$ ).

$$
\begin{aligned}
& A_{\text {bld }}^{\text {roof }}=1 \\
& A_{\text {bld }}^{\text {floor }}=1
\end{aligned}
$$

The ratio between the wall $\left(A_{\text {bld }}^{\text {wall }}\right)$ and window $\left(A_{\text {bld }}^{\text {win }}\right)$ surfaces and the building ground surface are given by Eqs. (B3) and (B4).

$A_{\text {bld }}^{\text {wall }}=\frac{A_{\text {hor }}^{\mathrm{fac}}\left(1-f_{\mathrm{glaz}}\right)}{f_{\mathrm{bld}}}$

$A_{\text {bld }}^{\text {win }}=\frac{A_{\text {hor }}^{\text {fac }} f_{\text {glaz }}}{f_{\text {bld }}}$

In Eqs. (B3) and (B4), $f_{\text {bld }}$ corresponds to the building density, which is the fraction of horizontal surface covered by buildings (Fig. 5a), $f_{\text {glaz }}$ to the glazing ratio, which is the fraction of the façade covered by windows and $A_{\text {hor }}^{\text {fac }}$ to the façade surface density, which is the ratio between the building façade surface and the horizontal surface (Fig. 5c). $f_{\text {bld }}$, $f_{\text {glaz }}$ and $A_{\text {hor }}^{\text {fac }}$ are input parameters of TEB.

The ratio between the surface of the internal mass and the building ground surface $\left(A_{\text {bld }}^{\text {mass }}\right)$ is given by Eq. (B5). There is no internal mass in one-storey buildings.

$A_{\text {bld }}^{\text {mass }}=2\left(N_{\text {floor }}-1\right)$ 
The number of floors $\left(N_{\text {floor }}\right)$ is given by Eq. (B6).

$$
N_{\text {floor }}=\operatorname{NINT}\left(\frac{H_{\text {bld }}}{H_{\text {floor }}}\right)
$$

$H_{\text {bld }}$ is the building height, $H_{\text {floor }}$ the floor height. Both are input parameters of TEB. NINT denotes the "nearest integer" function in Fortran90.

\section{B2 View factors}

The view factors between the different indoor facets are different for one-storey and multi-storey buildings. For onestorey buildings, the roof and the ground floor exchange long-wave radiation, whereas this is not the case for multistorey buildings. Instead, the roof and the ground floor exchange long-wave radiation with the internal mass.

The view factor of the window by the mass $\left(V_{\text {mass }}^{\text {win }}\right)$ is given by Eq. (B7).

$V_{\text {mass }}^{\text {win }}= \begin{cases}\frac{A_{\mathrm{bld}}^{\text {win }} V_{\mathrm{win}}^{\text {mass }}}{A_{\mathrm{bld}}^{\text {mass }}}, & \text { if } N_{\text {floor }}>1 \\ 0, & \text { otherwise }\end{cases}$

The view factor of the mass by the window $\left(V_{\text {win }}^{\text {mass }}\right)$ is given by Eq. (B8).

$V_{\text {win }}^{\operatorname{mass}}= \begin{cases}\frac{\left(1-V_{\text {floor }}^{\text {mass }}\right)\left(2 N_{\text {floor }}-2\right)}{2 \mathrm{HWR} N_{\text {floor }}}, & \text { if } N_{\text {floor }}>1 \\ 0, & \text { otherwise }\end{cases}$

The height-to-width ratio (HWR) of the floor levels is given by Eq. (B9), the view factors of the mass by the floor for multi-storey buildings ( $\left.V_{\text {floor }}^{\text {mass }}\right)$ or roof for one-storey buildings $\left(V_{\text {floor }}^{\text {roof }}\right)$ are given by Eqs. (B10) and (B11).

$$
\begin{aligned}
\text { HWR } & =\frac{A_{\text {hor }}^{\text {fac }}}{2 N_{\text {floor }} f_{\text {bld }}} \\
V_{\text {floor }}^{\text {mass }} & =\sqrt{\mathrm{HWR}^{2}+1}-\text { HWR } \\
V_{\text {floor }}^{\text {roof }} & =\sqrt{\mathrm{HWR}^{2}+1}-\mathrm{HWR}
\end{aligned}
$$

The view factors of the window by the floor and the roof are identical ( $\left.V_{\text {floor }}^{\text {win }}\right)$ and are given by Eq. (B12).

$$
V_{\text {floor }}^{\text {win }}=f_{\text {glaz }}\left(1-\left(\sqrt{\mathrm{HWR}^{2}+1}-\mathrm{HWR}\right)\right)
$$

The view factor of the window by the wall $\left(V_{\text {wall }}^{\text {win }}\right)$ is given by Eq. (B13).

$V_{\text {wall }}^{\text {win }}= \begin{cases}f_{\text {glaz }}\left(1-\frac{1-V_{\text {floor }}^{\text {mass }}}{H W R}\right), & \text { if } N_{\text {floor }}>1 \\ f_{\text {glaz }}\left(1-\frac{1-V_{\text {floor }}^{\text {roor }}}{H W R}\right), & \text { otherwise }\end{cases}$

The view factor of the window by the window of the opposite wall $\left(V_{\mathrm{win}}^{\mathrm{win}}\right)$ is given by Eq. (B14).

$V_{\text {win }}^{\text {win }}= \begin{cases}f_{\text {glaz }}\left(1-2 V_{\text {win }}^{\text {floor }}-V_{\text {win }}^{\text {mass }}\right), & \text { if } N_{\text {floor }}>1 \\ f_{\text {glaz }}\left(1-2 V_{\text {win }}^{\text {floor }}\right), & \text { otherwise }\end{cases}$

The view factor of the floor by the window ( $\left.V_{\text {win }}^{\text {floor }}\right)$ is given by Eq. (B15).

$$
V_{\text {win }}^{\text {floor }}= \begin{cases}\frac{1-V_{\text {floor }}^{\text {mass }}}{2 \mathrm{HWR} N_{\text {floor }}}, & \text { if } N_{\text {floor }}>1 \\ \frac{1-V_{\text {floor }}^{\text {roor }}}{2 \mathrm{HWR}}, & \text { otherwise }\end{cases}
$$




\section{Appendix C: List of symbols}

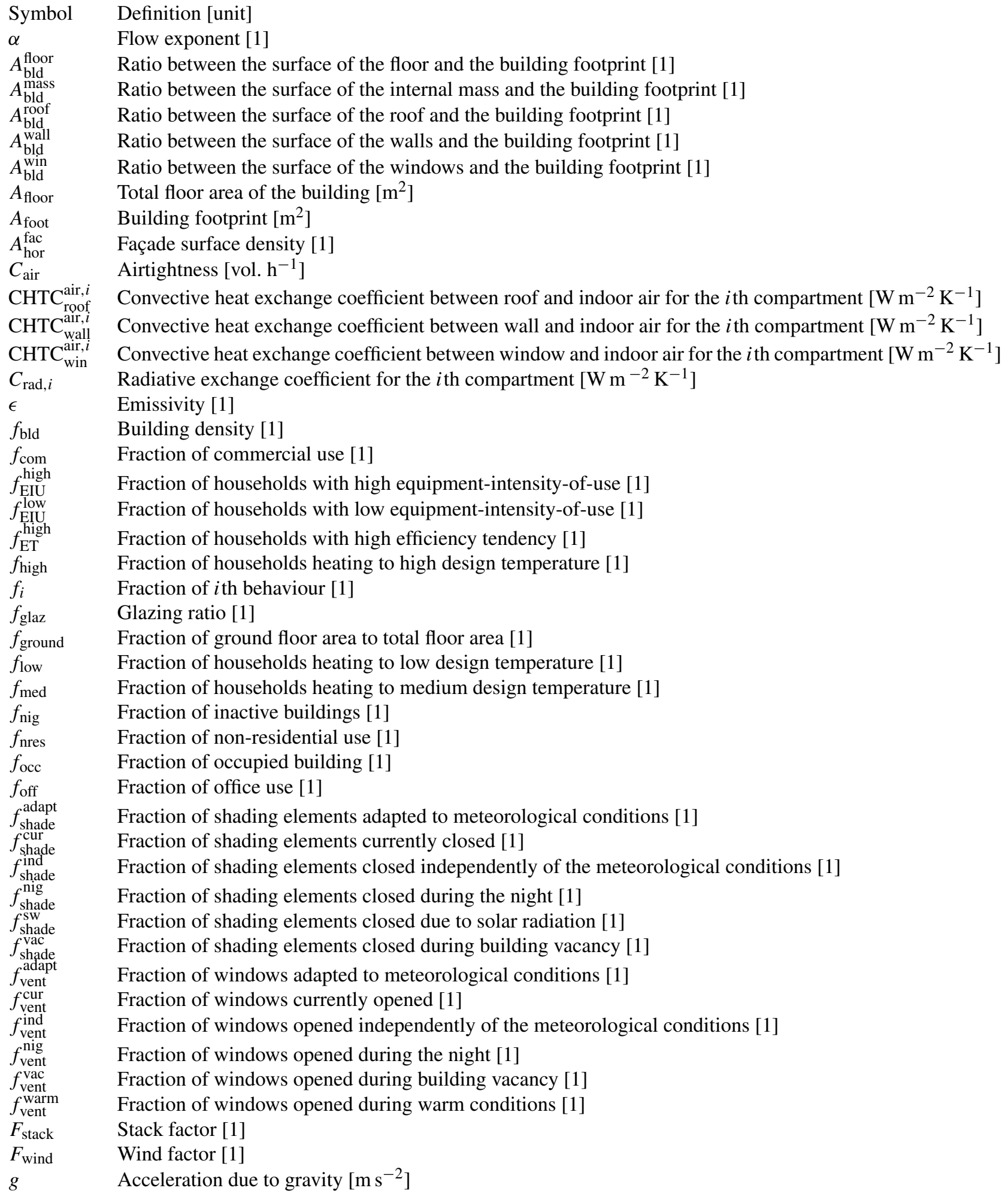


$H_{\text {bld }} \quad$ Building height $[\mathrm{m}]$

$H_{\text {floor }} \quad$ Floor height [m]

$H_{\text {flue }} \quad$ Normalised flue height [1]

$H_{\text {roof }}^{\text {ind }} \quad$ Heat flux due to convection from roof to indoor air [ $\mathrm{W} \mathrm{m}^{-2}$ ]

$H_{\text {wall }}^{\text {ind }} \quad$ Heat flux due to convection from wall to indoor air $\left[\mathrm{W} \mathrm{m}^{-2}\right]$

$H_{\text {waste, } i}^{\text {can }}$ Sensible waste heat flux from the indoor air of the $i$ th compartment towards the street canyon [W m ${ }^{-2}$ (façade)]

$H_{\text {waste, } i}^{\text {roof }} \quad$ Sensible waste heat flux from the indoor air of the $i$ th compartment towards the air above the roof [W m $\mathrm{W}^{-2}$ (roof)]

$H_{\text {win }}^{\text {ind }} \quad$ Heat flux due to convection from window to indoor air [ $\left.\mathrm{W} \mathrm{m}^{-2}\right]$

HWR Height-to-width ratio of the floor levels [1]

$I_{\text {stack }} \quad$ Air exchange rate due to stack effect [vol. $\mathrm{h}^{-1}$ ]

$I_{\text {tot }} \quad$ Total air exchange rate due to infiltration [vol. $\mathrm{h}^{-1}$ ]

$I_{\text {wind }} \quad$ Air exchange rate due to wind forcing [ $\mathrm{vol} . \mathrm{h}^{-1}$ ]

$\mathrm{LE}_{\text {waste, } i}^{\mathrm{can}} \quad$ Latent waste heat flux from the indoor air of the $i$ th compartment towards the street canyon [W m ${ }^{-2}$ (façade)]

$\mathrm{LE}_{\text {waste, } i}^{\text {roof }}$ Latent waste heat flux from the indoor air of the $i$ th compartment towards the air above the roof [W m ${ }^{-2}$ (roof)]

$\mathrm{LS}_{\mathrm{vac}} \quad$ Switch for shading during building vacancy [1]

$\mathrm{LW}_{\text {roof }}^{\text {floor }}$ Heat flux due to long-wave radiation from roof to floor [ $\left.\mathrm{W} \mathrm{m}^{-2}\right]$

$\mathrm{LW}_{\text {roof }}^{\text {mass }} \quad$ Heat flux due to long-wave radiation from roof to internal mass [ $\left.\mathrm{W} \mathrm{m}^{-2}\right]$

$\mathrm{LW}_{\text {wall }}^{\text {floor }} \quad$ Heat flux due to long-wave radiation from wall to floor $\left[\mathrm{W} \mathrm{m}^{-2}\right.$ ]

$\mathrm{LW}_{\text {wall }}^{\text {mass }} \quad$ Heat flux due to long-wave radiation from wall to internal mass $\left[\mathrm{W} \mathrm{m}^{-2}\right]$

$\mathrm{LW}_{\text {win }}^{\text {floor }} \quad$ Heat flux due to long-wave radiation from window to floor [ $\mathrm{W} \mathrm{m}^{-2}$ ]

$\mathrm{LW}_{\text {win }}^{\text {mass }} \quad$ Heat flux due to long-wave radiation from window to internal mass [W $\mathrm{m}^{-2}$ ]

$\mathrm{LV}_{\text {nig }} \quad$ Switch for ventilation during the night [1]

$M_{\text {nig }} \quad$ Modulation factor for internal heat release during night [1]

$M_{\text {vac }} \quad$ Modulation factor for internal heat release when the building is vacant [1]

$N \quad$ Number of considered fractional behaviours [1]

$N_{\text {floor }} \quad$ Number of floors in building [1]

$N_{\text {inh }} \quad$ Number of building inhabitants [1]

$p_{T-\text { high }}^{\text {HighET }} \quad$ Probability that a household heats to the high design temperature given that it falls into the high efficiency tendency class [1]

$p_{T \text {-high }}^{\text {LowET }} \quad$ Probability that a household heats to the high design temperature given that it falls into the low efficiency tendency class [1]

$p_{T-\text { low }}^{\text {HighET }} \quad$ Probability that a household heats to the low design temperature given that it falls into the high efficiency tendency class [1]

$p_{T-\text { low }}^{\text {LowET }} \quad$ Probability that a household heats to the low design temperature given that it falls into the low efficiency tendency class [1]

$p_{T-\text { med }}^{\text {HighET }}$

Probability that a household heats to the medium design temperature given that it falls into the high efficiency tendency class [1]

$p_{T-\text { med }}^{\text {LowET }} \quad$ Probability that a household heats to the medium design temperature given that it falls into the low efficiency tendency class [1]

$Q_{\text {ant }} \quad$ Anthropogenic heat flux $\left[\mathrm{W} \mathrm{m}^{-2}\right]$

$Q_{\text {floor }, i} \quad$ Heat load due to solar radiation and the radiative part of the internal heat release on the floor of the $i$ th compartment $\left[\mathrm{W} \mathrm{m}^{-2}\right]$

$Q_{\text {lat }} \quad$ Turbulent flux of latent heat $\left[\mathrm{W} \mathrm{m}^{-2}\right]$

$Q_{\text {mass }, i} \quad$ Heat load due to solar radiation and the radiative part of the internal heat release on the internal mass of the $i$ th compartment $\left[\mathrm{W} \mathrm{m}^{-2}\right]$

$Q_{\text {roof }} \quad$ Heat load due to solar radiation and the radiative part of the internal heat release on the indoor surface of the roof $\left[\mathrm{W} \mathrm{m}^{-2}\right]$

$Q_{\text {sen }} \quad$ Turbulent flux of sensible heat $\left[\mathrm{W} \mathrm{m}^{-2}\right]$

$Q_{\text {sto }} \quad$ Storage heat flux $\left[\mathrm{W} \mathrm{m}^{-2}\right]$

$Q_{\text {wall }} \quad$ Heat load due to solar radiation and the radiative part of the internal heat release on the indoor surface of the wall $\left[\mathrm{W} \mathrm{m}^{-2}\right]$

$Q_{\text {win }} \quad$ Heat load due to solar radiation and the radiative part of the internal heat release on the indoor surface of the window $\left[\mathrm{W} \mathrm{m}^{-2}\right]$ 


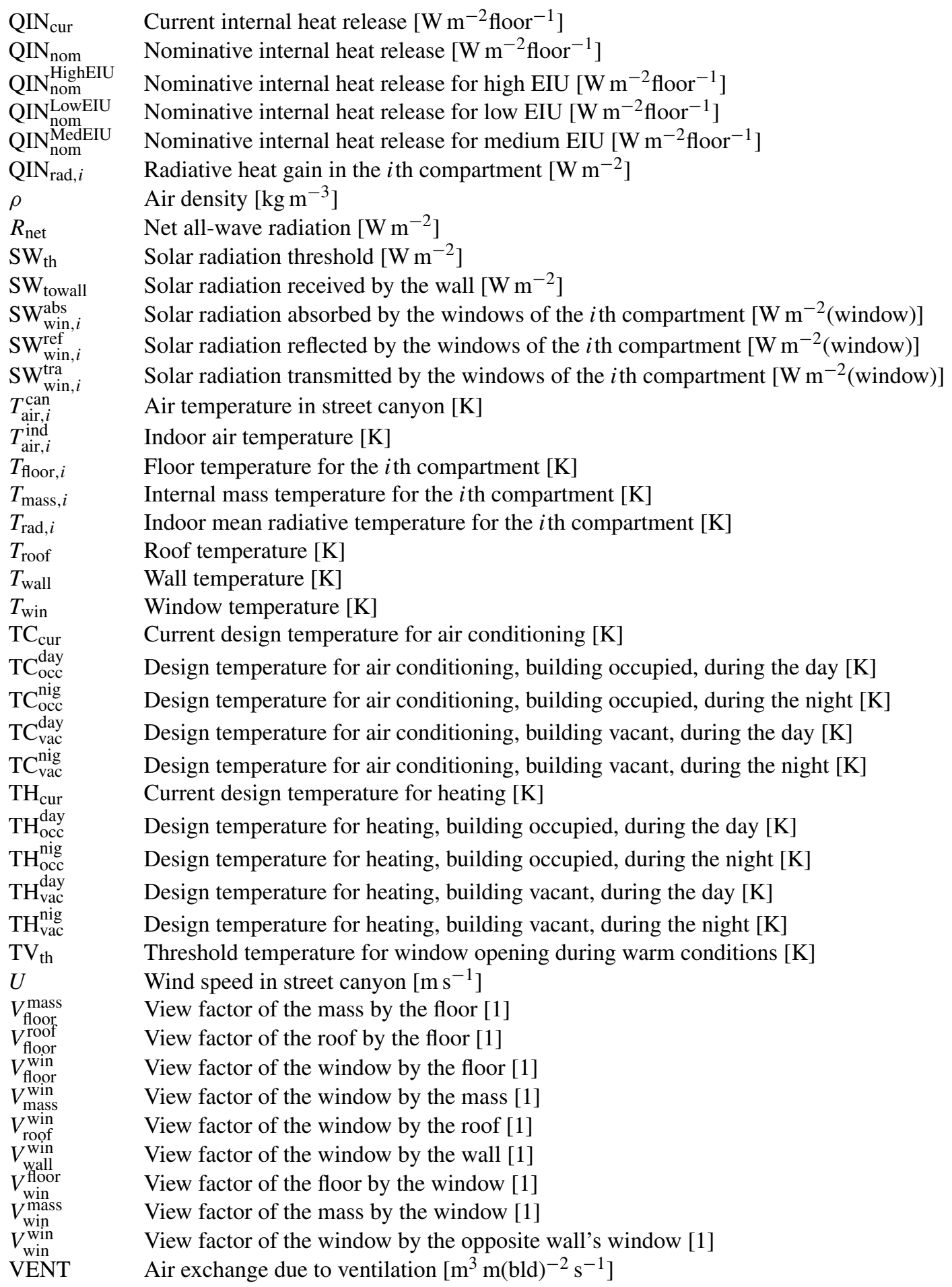


Competing interests. The authors declare that they have no conflict of interest.

Acknowledgements. We thank Grégoire Pigeon for providing original code and data required for the construction of the inventory of building energy consumption and for discussions concerning the building energy model in TEB. Erwan Bocher and Gwendall Petit are acknowledged for making available data characterising urban morphology via the MApUCE toolbox in the OrbisGis software. Alexandre Amossé is acknowledged for providing data on urban typology. Pauline Crombette, Julia Hidalgo and Najla Touati are acknowledged for providing data on urban vegetation. This work has received support from the French National Agency of Research for the project applied Modelling and urbAn Planning laws: Urban Climate and Energy (MApUCE) with the reference ANR-13-VBDU-0004.

Edited by: Jatin Kala

Reviewed by: three anonymous referees

\section{References}

Akbari, H., Matthews, H. D., and Seto, D.: The long-term effect of increasing the albedo of urban areas, Environ. Res. Lett., 7, 024004, https://doi.org/10.1088/1748-9326/7/2/024004, 2012.

Amossé, A.: Identification automatique d'une typologie urbaine des îlots urbains en France, Tech. rep., Laboratoire de recherche en architecture, Laboratoire de recherche en architecture, Toulouse, France, 2015.

Andersen, R., Fabi, V., Toftum, J., Corgnati, S. P., and Olesen, B. W.: Window opening behaviour modelled from measurements in Danish dwellings, Build. Environ., 69, 101-113, https://doi.org/10.1016/j.buildenv.2013.07.005, 2013.

Andersen, R. K.: The influence of occupants behaviour on energy consumption investigated in 290 identical dwellings and in 35 apartments, in: 10th International Conference on Healthy Buildings - Brisbane, Australia, 2012.

Arnfield, A. J.: Two decades of urban climate research: a review of turbulence, exchanges of energy and water, and the urban heat island, Int. J. Climatol., 23, 1-26, https://doi.org/10.1002/joc.859, 2003.

Blazejczyk, K., Epstein, Y., Jendritzky, G., Staiger, H., and Tinz, B.: Comparison of UTCI to selected thermal indices, Int. J. Biometeorol., 56, 515-535, https://doi.org/10.1007/s00484-011-0453-2, 2012.

Bourgeois, A., Pellegrino, M., and Lévy, J.-P.: Modeling and mapping domestic energy behavior: Insights from a consumer survey in France, Energy Research and Social Science, https://doi.org/10.1016/j.erss.2017.06.021, in press, 2017.

Bueno, B., Pigeon, G., Norford, L. K., Zibouche, K., and Marchadier, C.: Development and evaluation of a building energy model integrated in the TEB scheme, Geosci. Model Dev., 5, 433-448, https://doi.org/10.5194/gmd-5-433-2012, 2012.

Chow, W. T., Salamanca, F., Georgescu, M., Mahalov, A., Milne, J. M., and Ruddell, B. L.: A multi-method and multi-scale approach for estimating city-wide an- thropogenic heat fluxes, Atmos. Environ., 99, 64-76, https://doi.org/10.1016/j.atmosenv.2014.09.053, 2014.

Christen, A. and Vogt, R.: Energy and radiation balance of a central European city, Int. J. Climatol., 24, 1395-1421, https://doi.org/10.1002/joc.1074, 2004.

Crombette, P., Le Corre, S., and Tinel, C.: Traitement d'images satellitaires à Très Haute Résolution Spatiale et identification de zones à enjeux dans l'aménagement des Trames Vertes urbaines, Revue Française de Photogrammétrie et de Télédétection, available at: http://www.sfpt.fr/rfpt/index.php/RFPT/article/view/130 (last access: 20 July 2017), 2014.

de Meester, T., Marique, A.-F., Herde, A. D., and Reiter, S.: Impacts of occupant behaviours on residential heating consumption for detached houses in a temperate climate in the northern part of Europe, Energ. Buildings, 57, 313-323, https://doi.org/10.1016/j.enbuild.2012.11.005, 2013.

de Munck, C., Pigeon, G., Masson, V., Meunier, F., Bousquet, P., Tréméac, B., Merchat, M., Poeuf, P., and Marchadier, C.: How much can air conditioning increase air temperatures for a city like Paris, France?, Int. J. Climatol., 33, 210-227, https://doi.org/10.1002/joc.3415, 2013.

EC: Ventilation for buildings-Calculation methods for the determination of air flow rates in buildings including infiltration, Tech. rep., European Commission, Secretariat BSI, 2006.

Fabi, V., Andersen, R. V., Corgnati, S. P., and Olesen, B. W.: A methodology for modelling energy-related human behaviour: Application to window opening behaviour in residential buildings, Building Simulation, 6, 415-427, https://doi.org/10.1007/s12273-013-0119-6, 2013.

Grimmond, C. S. B.: The suburban energy balance: Methodological considerations and results for a mid-latitude west coast city under winter and spring conditions, Int. J. Climatol., 12, 481-497, https://doi.org/10.1002/joc.3370120506, 1992.

Guerra Santin, O.: Occupant behaviour in energy efficient dwellings: evidence of a rebound effect, Journal of Housing and the Built Environment, 28, 311-327, https://doi.org/10.1007/s10901-012-9297-2, 2013.

Haldi, F. and Robinson, D.: Adaptive actions on shading devices in response to local visual stimuli, Journal of Building Performance Simulation, 3, 135-153, https://doi.org/10.1080/19401490903580759, 2010.

Haldi, F. and Robinson, D.: The impact of occupants' behaviour on building energy demand, Journal of Building Performance Simulation, 4, 323-338, https://doi.org/10.1080/19401493.2011.558213, 2011.

Hamdi, R. and Masson, V.: Inclusion of a Drag Approach in the Town Energy Balance (TEB) Scheme: Offline 1D Evaluation in a Street Canyon, J. Appl. Meteorol. Climatol., 47, 2627-2644, https://doi.org/10.1175/2008JAMC1865.1, 2008.

Hamilton, I. G., Davies, M., Steadman, P., Stone, A., Ridley, I., and Evans, S.: The significance of the anthropogenic heat emissions of London's buildings: A comparison against captured shortwave solar radiation, Building and Environment, 44, 807-817, https://doi.org/10.1016/j.buildenv.2008.05.024, 2009.

Heiple, S. and Sailor, D. J.: Using building energy simulation and geospatial modeling techniques to determine high resolution building sector energy consumption profiles, Energy and Buildings, 40, 1426-1436, https://doi.org/10.1016/j.enbuild.2008.01.005, 2008. 
Hosni, M. H., Jones, B. W., and Xu, H.: Experimental Results for Heat Gain and Radiant/Convective Split from Equipment in Buildings, ASHRAE TRANSACTIONS, 105, 1999.

Kanda, M., Kanega, M., Kawai, T., Moriwaki, R., and Sugawara, H.: Roughness Lengths for Momentum and Heat Derived from Outdoor Urban Scale Models, J. Appl. Meteorol. Climatol., 46, 1067-1079, https://doi.org/10.1175/JAM2500.1, 2007.

Kelly, S., Shipworth, M., Shipworth, D., Gentry, M., Wright, A., Pollitt, M., Crawford-Brown, D., and Lomas, K.: Predicting the diversity of internal temperatures from the English residential sector using panel methods, Appl. Energy, 102, 601-621, https://doi.org/10.1016/j.apenergy.2012.08.015, 2013.

Kikegawa, Y., Genchi, Y., Yoshikado, H., and Kondo, H.: Development of a numerical simulation system toward comprehensive assessments of urban warming countermeasures including their impacts upon the urban buildings' energy-demands, Appl. Energ., 76, 449-466, https://doi.org/10.1016/S0306-2619(03)00009-6, 2003.

Kunze, C. and Hecht, R.: Semantic enrichment of building data with volunteered geographic information to improve mappings of dwelling units and population, Computers, Environment and Urban Systems, 53, 4-18, https://doi.org/10.1016/j.compenvurbsys.2015.04.002, 2015.

Kusaka, H., Kondo, H., Kikegawa, Y., and Kimura, F.: A Simple Single-Layer Urban Canopy Model For Atmospheric Models: Comparison With Multi-Layer And Slab Models, Bound.-Lay. Meteorol., 101, 329-358, https://doi.org/10.1023/A:1019207923078, 2001.

Kłysik, K.: Spatial and seasonal distribution of anthropogenic heat emissions in Lodz, Poland, Atmos. Environ., 30, 3397-3404, https://doi.org/10.1016/1352-2310(96)00043-X, 1996.

Lemonsu, A., Masson, V., Shashua-Bar, L., Erell, E., and Pearlmutter, D.: Inclusion of vegetation in the Town Energy Balance model for modelling urban green areas, Geosci. Model Dev., 5, 1377-1393, https://doi.org/10.5194/gmd-5-1377-2012, 2012.

Lévy, J.-P. and Roudil, N.: La consommation énergétique domestique: le projet ENERGIHAB, in: Colloque "Usages de l'énergie dans les bâtiments ", ESIEE Paris, Cité Descartes, France, available at: https://hal.archives-ouvertes.fr/hal-01072070/ (last access: 20 July 2017), 2012.

Martilli, A., Clappier, A., and Rotach, M. W.: An Urban Surface Exchange Parameterisation for Mesoscale Models, Bound.-Lay. Meteorol., 104, 261-304, https://doi.org/10.1023/A:1016099921195, 2002.

Masson, V.: A Physically-Based Scheme For The Urban Energy Budget In Atmospheric Models, Bound.-Lay. Meteorol., 94, 357-397, https://doi.org/10.1023/A:1002463829265, 2000.

Masson, V., Gomes, L., Pigeon, G., Liousse, C., Pont, V., Lagouarde, J.-P., Voogt, J., Salmond, J., Oke, T. R., Hidalgo, J., Legain, D., Garrouste, O., Lac, C., Connan, O., Briottet, X., Lachérade, S., and Tulet, P.: The Canopy and Aerosol Particles Interactions in TOulouse Urban Layer (CAPITOUL) experiment, Meteorol. Atmos. Phys., 102, 135, https://doi.org/10.1007/s00703-008-0289-4, 2008.

MEDDE: Les conditions d'occupation des logements au 1er janvier 2011, Tech. rep., Ministère de l'Ecologie, du Développement durable et de l'Energie, 2012.

Mironov, D., Heise, E., Kourzeneva, E., Ritter, B., Schneider, N., and Terzhevik, A.: Implementation of the lake parameterisa- tion scheme FLake into the numerical weather prediction model COSMO, Boreal Environ. Res., 15, 218-230, 2010.

Motuziene, V. and Vilutiene, T.: Modelling the Effect of the Domestic Occupancy Profiles on Predicted Energy Demand of the Energy Efficient House, Procedia Engineering, 57, 798-807, https://doi.org/10.1016/j.proeng.2013.04.101, 2013.

Nie, W.-S., Sun, T., and Ni, G.-H.: Spatiotemporal characteristics of anthropogenic heat in an urban environment: A case study of Tsinghua Campus, Build. Environ., 82, 675-686, https://doi.org/10.1016/j.buildenv.2014.10.011, 2014.

Noilhan, J. and Planton, S.: A Simple Parameterization of Land Surface Processes for Meteorological Models, Mon Weather Rev., 117, 536-549, https://doi.org/10.1175/15200493(1989)117<0536:ASPOLS>2.0.CO;2, 1989.

Oke, T. R.: The energetic basis of the urban heat island, Q. J. Roy. Meteor. Soc., 108, 1-24, https://doi.org/10.1002/qj.49710845502, 1982.

Oleson, K. W., Bonan, G. B., Feddema, J., Vertenstein, M., and Grimmond, C. S. B.: An Urban Parameterization for a Global Climate Model. Part I: Formulation and Evaluation for Two Cities, J. Appl. Meteorol. Clim., 47, 1038-1060, https://doi.org/10.1175/2007JAMC1597.1, 2008.

Pigeon, G., Legain, D., Durand, P., and Masson, V.: Anthropogenic heat release in an old European agglomeration (Toulouse, France), Int. J. Climatol., 27, 1969-1981, https://doi.org/10.1002/joc.1530, 2007.

Pigeon, G., Zibouche, K., Bueno, B., Bras, J. L., and Masson, V.: Improving the capabilities of the Town Energy Balance model with up-to-date building energy simulation algorithms: an application to a set of representative buildings in Paris, Energy and Buildings, 76, 1-14, https://doi.org/10.1016/j.enbuild.2013.10.038, 2014.

Raja, I. A., Nicol, J., McCartney, K. J., and Humphreys, M. A.: Thermal comfort: use of controls in naturally ventilated buildings, Energy and Buildings, 33, 235-244, https://doi.org/10.1016/S0378-7788(00)00087-6, 2001.

Roetzel, A., Tsangrassoulis, A., Dietrich, U., and Busching, S.: A review of occupant control on natural ventilation, Renewable and Sustainable Energy Reviews, 14, 1001-1013, https://doi.org/10.1016/j.rser.2009.11.005, 2010.

Sailor, D. and Pavlova, A.: Air conditioning market saturation and long-term response of residential cooling energy demand to climate change, Energy, 28, 941-951, https://doi.org/10.1016/S0360-5442(03)00033-1, 2003.

Sailor, D. J.: A review of methods for estimating anthropogenic heat and moisture emissions in the urban environment, Int. J. Climatol., 31, 189-199, https://doi.org/10.1002/joc.2106, 2011.

Salamanca, F., Krpo, A., Martilli, A., and Clappier, A.: A new building energy model coupled with an urban canopy parameterization for urban climate simulations - part I. formulation, verification, and sensitivity analysis of the model, Theor. Appl. Climatol., 99, 331, https://doi.org/10.1007/s00704-009-0142-9, 2009.

Schoetter, R., Masson, V., Bourgeois, A., Pellegrino, M., and Lévy, J.-P.: Source code and run directories for Schoetter et al., GMD: Parametrisation of the variety of human behaviour related to building energy consumption in the Town Energy Balance (SURFEX-TEB v. 8.2), https://doi.org/10.5281/zenodo.818632, 2017. 
Shepherd, J. M.: A Review of Current Investigations of UrbanInduced Rainfall and Recommendations for the Future, Earth Interact., 9, 1-27, https://doi.org/10.1175/EI156.1, 2005.

Stewart, I. D. and Oke, T. R.: Local Climate Zones for Urban Temperature Studies, B. Am. Meteorol. Soc., 93, 1879-1900, https://doi.org/10.1175/BAMS-D-11-00019.1, 2012.

Thatcher, M. and Hurley, P.: Simulating Australian Urban Climate in a Mesoscale Atmospheric Numerical Model, Bound.-Lay. Meteorol., 142, 149-175, https://doi.org/10.1007/s10546-011-9663$8,2012$.

Tornay, N., Schoetter, R., Bonhomme, M., Faraut, S., and Masson, V.: GENIUS: A methodology to define a detailed description of buildings for urban climate and building energy consumption simulations, Urban Climate, 20, 75-93, https://doi.org/10.1016/j.uclim.2017.03.002, 2017.

Unger, J.: Urban-rural air humidity differences in Szeged, Hungary, Int. J. Climatol., 19, 1509-1515, https://doi.org/10.1002/(SICI)10970088(19991115)19:13<1509::AID-JOC453>3.0.CO;2-P, 1999.

Vorger, E.: Étude de l'influence du comportement des occupants sur la performance énergétique des bâtiments, $\mathrm{PhD}$ thesis, École nationale supérieure des mines de Paris, 2014.
Walker, I. and Wilson, D.: Field Validation of Algebraic Equations for Stack and Wind Driven Air Infiltration Calculations, Tech. rep., ASHRAE HVAC Research Journal, 4, 1998.

Wang, W., Beausoleil-Morrison, I., and Reardon, J.: Evaluation of the Alberta air infiltration model using measurements and intermodel comparisons, Building and Environment, 44, 309-318, https://doi.org/10.1016/j.buildenv.2008.03.005, 2009.

Wilke, U.: Probabilistic Bottom-up Modelling of Occupancy and Activities to Predict Electricity Demand in Residential Buildings, $\mathrm{PhD}$ thesis, École Polytechnique Fédérale De Lausanne, Lausanne, Switzerland, 2013.

Yang, L., Yan, H., and Lam, J. C.: Thermal comfort and building energy consumption implications - A review, Appl. Energ., 115, 164-173, https://doi.org/10.1016/j.apenergy.2013.10.062, 2014.

Yun, G. Y., Kim, H., and Kim, J. T.: Effects of occupancy and lighting use patterns on lighting energy consumption, Energy and Buildings, 46, 152-158, https://doi.org/10.1016/j.enbuild.2011.10.034, 2012. 